\title{
Does engagement with frontline health workers improve maternal and child healthcare utilisation and outcomes in India?
}

\section{Anu Rammohan}

UWA: University of Western Australia

Srinivas Goli ( $\square$ srinivas.goli@uwa.edu.au )

University of Western Australia https://orcid.org/0000-0002-8481-484X

Shashi Kala Saroj

Jawaharlal Nehru University

Abdul Jaleel CP

University of Delhi

\section{Research}

Keywords: Frontline Health Workers, Health services, Maternal health, Child health, Child mortality, Antenatal care, Delivery care, Postnatal care, India

Posted Date: October 9th, 2020

DOl: https://doi.org/10.21203/rs.3.rs-87405/v1

License: (c) (i) This work is licensed under a Creative Commons Attribution 4.0 International License. Read Full License

Version of Record: A version of this preprint was published at Human Resources for Health on April 1st, 2021. See the published version at https://doi.org/10.1186/s12960-021-00592-1. 
Does engagement with frontline health workers improve maternal and child healthcare utilisation and outcomes in India?

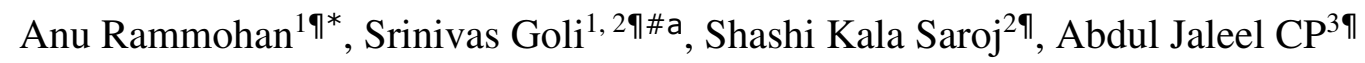

${ }^{1}$ The University of Western Australia (M251), Crawley, Western Australia, Australia

${ }^{2}$ Jawaharlal Nehru University, New Delhi, India

${ }^{3}$ UNICEF National Centre of Excellence and Advanced Research on Diets, Lady Irwin College, University of Delhi, New Delhi, India

\#a Current Address: Australia India Institute, UWA Public Policy Institute, University of Western Australia, Crawley, Western Australia, Australia

*srinivas.goli@uwa.edu.au

http://orcid.org/0000-0002-8481-484X

I These authors contributed equally to this work.

Abbreviations: ANM, Auxiliary Nurse Midwife; ASHA, Accredited Social Health Activist; AWW, Anganwadi Worker; BLR, Binary Logistic Regression; FHWE, Frontline Health Worker Engagement; MCH, Maternal, and Child Health; NFHS, National Family Health Survey; NHM, National Health Mission 


\begin{abstract}
Background

Poor Maternal and Child Health (MCH) outcomes pose challenges to India's ability to attain Goal-3 of the Sustainable Development Goals (SDGs). The government of India strengthened the existing network of Frontline Health Workers (FHWs), under its National Rural Health Mission in 2005 and subsequent National Urban Health Mission in 2013 as a strategy to mitigate the shortage of skilled health workers and to provide affordable healthcare services. However, there is a lack of robust national-level empirical analysis on the role of maternal engagement with FHWs in influencing the level of maternal and child health care utilisation and child health outcomes in India.
\end{abstract}

\title{
Methods
}

Using data from the nationally representative Indian National Family Health Survey (NFHS) 2015-16, this paper aims to investigate the intensity of engagement of FHWs with married women of child-bearing age (15-49 years), its influence on utilisation of maternal and child healthcare services, and child health outcomes. Our empirical analyses use multivariate regression analyses, focusing on five maternal and child health indicators: antenatal care visits (ANC) (4 or >4 times), institutional delivery, full-immunisation of children, postnatal care (PNC) (within 2 days of delivery), and child survival.

\section{Results}

Our analysis finds that maternal engagement with FHWs is statistically significant and a positive predictor of maternal and child health care utilisation, and child survival. Further, the level of engagement with FHWs is particularly important for women from economically poor households. Our robustness checks across sub-samples of women who delivered only in public 
health institutions and those from rural areas provides an additional confidence in our main results.

\section{Conclusions}

From a policy perspective, our findings highlight that strengthening the network of FHWs in the areas where they are in shortage which can help in further improving the utilisation of maternal and child healthcare services, and health outcomes.

\section{Keywords}

Frontline Health Workers, Health services, Maternal health, Child health, Child mortality, Antenatal care, Delivery care, Postnatal care, India 


\section{Background}

Despite a decline in Under-Five Mortality Rate (U5MR) in India from 126 per 1,000 live births in 1990 to 37 per 1,000 live births in 2018, poor Maternal and Child Health (MCH) outcomes pose challenges to India's ability to attain Goal-3 of the Sustainable Development Goals (SDGs). Specifically, Goal 3.2 seeks to 'reduce the global neonatal mortality and U5MR to at least 12 per 1000 live births and 25 per 1000 live births by 2030 [1-2]. Figs from India's countrywide representative 2015-16 National Family Health Survey (NFHS) show that 21\% of live births did not have skilled attendance, $49 \%$ of pregnant women did not receive basic antenatal care, and approximately $76 \%$ of new-born babies did not receive health care within two days of birth. Furthermore, the proportion of children who did not receive any vaccination has increased in 2015-16 compared to 2005-06 [3].

Researchers have attributed these poor maternal and child health outcomes to low levels of health care utilisation during pregnancy and childbirth [4-6]. Low levels of health care utilisation may be due to demand-side factors such as poverty, lack of education, rural residence or other socio-economic deprivations [7-11]. Other researchers have proposed supply-side reasons such as poor availability, accessibility, and inequality in accessing health care resources [12-16].

Studies from a wide range of settings have shown that greater access to Frontline Health Workers (FHWs) and Community Health Workers (CHW) can greatly improve maternal and child health care utilisation and outcomes. FHWs play an important role in disseminating community-based health information and encouraging the utilisation of $\mathrm{MCH}$ and family planning services $[13,17-23]$. FHWs directly interact with women and their family members, particularly in poor and remote disadvantaged communities [21, 23-25]. They perform tasks such as increasing awareness of hygiene and sanitation practices, making a timely referral of patients to health facilities, monitoring, and play an important role in the supervision of health 
and nutrition programs at the community level, reporting of vital events and motivating women to access essential care from health facilities [26-27]. Health workers, in particular, FHWs are an integral part of improving $\mathrm{MCH}$ care utilisation, particularly in rural areas of developing countries, with low access to health services [19]. FHWs are typically health care workers who deliver routine and essential services in public health or medical practice. They encompass a wide variety of local healthcare providers ranging from salaried-staff, midwives, nurses to home-based caregivers, and volunteers, with their functions varying across countries [28-29].

In India, although the role of FHWs is not empirically analysed at the national level, small sample case studies have shown that greater access to FHWs can greatly improve $\mathrm{MCH}$ care utilisation and outcomes $[13,14,18,30-32]$. In India's health care delivery system, FHWs have an integral role to play in the supply of $\mathrm{MCH}$ services, particularly disseminating information about the government's flagship health care programmes among eligible beneficiaries such as pregnant women, mothers and their children [33]. Previous research suggests that the utilisation of maternal and child healthcare $(\mathrm{MCH})$ services has increased substantially since the launch of flagship $\mathrm{MCH}$ programmes (i.e. Integrated Child Development Schemes [ICDS] and National Health Mission (NHM) [4,34-36].

Furthermore, although workers such as Auxiliary Nurse Midwives (ANM) and Anganwadi workers have been around since the 1950s and 1970s respectively, the aim of enhancing primary health care in villages has increased their importance as a link between health services and the community [37-38]. The existing network of FHWs was strengthened in 2005, under the Government of India's National Rural Health Mission, and in 2013 under the National Urban Health Mission, as a strategy to mitigate the shortage of skilled health workers, and to provide affordable healthcare services to vulnerable groups [13, 21, 37-40]. Therefore, it is important to identify the role of FHWs in improving access to MCH care. 
However, there is a lack of robust national-level evidence on the association of engagement with FHWs and MCH care and outcomes.

A PubMed search for studies on maternal and child health care with keywords of "determinants of maternal and child health care in India" shows that just two out of the top 100 search results (studies) have investigated the role of FHWs/ CHWs in MCH care and outcomes. Thus, our study seeks to address the research gap on the role of maternal engagement with FHWs in influencing the level of $\mathrm{MCH}$ care utilisation and child health outcomes in India.

Against this background, our paper uses the nationally representative Indian NFHS to empirically analyse the level of engagement between the FHWs and married women of childbearing age (15-49 years), and its influence on the utilisation of MCH services and child health and survival outcomes. Our empirical analyses focus on five maternal and child health indicators- antenatal care visits (ANC) (4 or > 4 times), institutional delivery, full-immunisation of children, postnatal care (PNC) (within 2 days of delivery), and child survival.

Our paper makes several contributions to the literature. Firstly, previous research from India has focused mainly on the quality of service delivery system by FHWs [39-41], their impact on health inequality $[31,42,43]$, maternal and newborn health $[14,30]$, and maternity care $[13,18]$. However, a review conducted by [44] suggests that these studies use data that are based on small samples, experimental or case studies, and reviews studies, which makes it difficult to generalise their findings to the national level. Providing national-level evidence on the influence of FHWs on MCH outcomes is particularly critical from a policy perspective, given the heterogeneity across various geographical regions, socio-economic, and demographic groups.

Secondly, considering the federal structure of India's health care system and the diverse range of health policies and programmes across different states [45], it is important to identify the role of FHWs in enhancing $\mathrm{MCH}$ care and outcomes. In this direction, we use a 
comprehensive definition of FHWs encompassing various nomenclatures, work profiles, or functions used at the operational level in the government flagships programmes in different states. We have used 48 questions about the interactions of women with all categories of FHWs from multiple sections of the questionnaire schedule which were repeatedly asked at the different stages of pregnancy, childbirth, and new-born care in different forms, which serve as strong robustness checks for response errors. Thus, our measure of FHWs provides a robust tool to capture their influence in enhancing $\mathrm{MCH}$ care and outcomes.

Thirdly, we contribute to the literature by investigating if engagement with FHWs affects $\mathrm{MCH}$ utilisation differentially across different sub-sample of populations: who delivered in public health hospitals and residing in rural areas. In other words, are women delivered in public health hospitals or those who belong to rural areas are more likely to benefit from engaging with FHWs than their counterparts? Since the flagship health programmes largely target vulnerable rural women by strengthening the public health care system, thus the robustness of our results were tested using sub-sample analyses [46]. Moreover, relative to previous studies, we use a more comprehensive measure of the level of FHWs engagement with women at the time of pregnancy, delivery and postnatal care. Thus, our study significantly adds to filling the research gap with national-level evidence.

\section{Methods}

\section{Data and sampling}

The data for this study come from the fourth round of India's 2015-16 National Family Health Survey (NFHS-4). The NFHS-4 is a nationally representative dataset of Indian households conducted by the International Institute for Population Sciences (IIPS), under the stewardship of the Ministry of Health and Family Welfare (MoHFW), Government of India. The household survey covered a sample of 601,509 households and 699,686 women aged 15- 
49 years. The survey used multi-stage cluster sampling with an overall response rate of $98 \%$. Details of sample design, including sampling frame and survey implementation, are provided elsewhere [3]. Moreover, the data used for this study are publicly available at The Demographic Health Surveys [DHS] website, thus do not require ethical approval [47].

The data on MCH care, outcomes, and female's engagement with health workers come from the Women's questionnaire, which was administered to women aged 15-49 years. Given the focus of our analysis on MCH care and outcomes, we only include those women who gave birth in the five years prior to the survey. The Women's questionnaire contains detailed information on the birth histories and details of all children born in the last five years. For these mothers, the survey provides detailed information on the socio-economic and demographic characteristics of the respondent and their households. Our final sample consists of 259,627 women aged 15-49 years (with 130,132 from poor households and 129,495 from non-poor households).

\section{Estimation strategy}

Outcome variables. The outcome variables in this study include five key MCH indicators. Four of these indicators relate to $\mathrm{MCH}$ services utilisation, while we also include child survival as an additional outcome indicator. Specifically, we include the following outcome variables: (i) ANC visits $=1$ if the respondent made at least 4+ antenatal visits during her last pregnancy, 0 otherwise; (ii) Institutional delivery $=1$ if the birth was at a public/private institution, 0 otherwise; (iii) Children's Full Immunisation (CFI) = 1 if a child (aged 12-23 months) received the full prescribed set of vaccinations. These are BCG (one dose), DPT (three doses), Polio (three doses), and Measles (one dose), 0 otherwise; (iv) Postnatal care (PNC)- whether the child received PNC from a doctor or skilled medical personnel in the first two days of birth; and finally, (v) Under-five child survival- whether or not the child is alive. 
Explanatory variables. Our main explanatory variable is an index called the Frontline Health Worker Engagement Index (FHWEI), which is constructed using information from responses to 48 questions on the female respondent's engagement with the following categories of FHWs: ANM/ASHA/Mid-wife/Lady health worker or other health workers/Multipurpose worker [MPW]/Anganwadi worker. Following [48] method of index construction using non-linear variables, the 48 variables considered for FHWEI have been dichotomised into two categories: 'engagement $=1$ ' and 'no engagement $=0$ '. The reliability of the variables used in the construction of the index is measured using Cronbach's coefficient. An alpha value of 0.94 indicates a high scale of reliability of the FHWEI Table A1. The composite score of FHWEI was divided into three equal categories i.e. 'Low', 'Medium', and 'High' quality of engagement.

Table A1. List of indicators considered for the Frontline Health Worker Engagement Index, 2015-16, [AIC: 0.0389, Coefficient: 0.9409]

\begin{tabular}{|c|c|c|c|c|}
\hline $\begin{array}{l}\text { S. } \\
\text { No. }\end{array}$ & & Indicators & $1^{\mathrm{a}}$ & $0^{\mathrm{b}}$ \\
\hline 1. & \multicolumn{2}{|c|}{ Pregnancy registered } & Yes $=1$ & No $=0$ \\
\hline 2. & \multicolumn{2}{|c|}{ Receives mother and child protection card after registration } & Yes $=1$ & No $=0$ \\
\hline 3. & \multirow{4}{*}{ Prenatal care } & ANM/nurse/mid-wife/LHV. & Yes $=1$ & No $=0$ \\
\hline 4. & & Community village health worker (CHW) & Yes $=1$ & No $=0$ \\
\hline 5. & & Anganwadi (AWW)/ ICDS worker & Yes $=1$ & No $=0$ \\
\hline 6. & & ASHA & Yes $=1$ & $\mathrm{No}=0$ \\
\hline \multirow{2}{*}{7.} & \multirow{2}{*}{$\begin{array}{l}\text { Assistance } \\
\text { provided by }\end{array}$} & ANM/nurse/ mid-wife/LHV & Yes $=1$ & No $=0$ \\
\hline & & Other health personnel & Yes $=1$ & $\mathrm{No}=0$ \\
\hline \multirow{3}{*}{$\begin{array}{l}9 . \\
10 . \\
11 .\end{array}$} & \multirow{3}{*}{$\begin{array}{l}\text { Antenatal care } \\
\text { (ANC) }\end{array}$} & Public Anganwadi/ ICDS Centre & Yes $=1$ & No $=0$ \\
\hline & & Public village clinic by ANM & Yes $=1$ & No $=0$ \\
\hline & & Other public village health facility & Yes $=1$ & $\mathrm{No}=0$ \\
\hline \multirow{2}{*}{$\frac{12 .}{13 .}$} & \multirow{2}{*}{$\begin{array}{l}\text { Pregnant woman } \\
\text { met with }\end{array}$} & ANM or LHV in last three months & Yes $=1$ & No $=0$ \\
\hline & & AWW/ ASHA/ other CHW in last three months & Yes $=1$ & No $=0$ \\
\hline 14. & \multirow{4}{*}{$\begin{array}{l}\text { Person met with the } \\
\text { pregnant woman }\end{array}$} & AWW & Yes $=1$ & $\mathrm{No}=0$ \\
\hline 15. & & ASHA & Yes $=1$ & No $=0$ \\
\hline 16. & & MPW & Yes $=1$ & No $=0$ \\
\hline 17. & & Other health worker & Yes $=1$ & No $=0$ \\
\hline 18. & \multirow{3}{*}{$\begin{array}{l}\text { During the last } 3 \\
\text { months of } \\
\text { pregnancy }\end{array}$} & visited health facility for self or child & Yes $=1$ & No $=0$ \\
\hline 19. & & person met during most recent contact & {$\left[\begin{array}{c}\text { ANM } \\
\text { LHV } \\
\text { AWW } \\
\text { ASHA } \\
\text { MPW }\end{array}\right]=1$} & Other $=0$ \\
\hline 20. & & Met with ANM/ LHV/ ASHA, Anganwadi worker & Yes $=1$ & No $=0$ \\
\hline 21. & \multirow{4}{*}{$\begin{array}{l}\text { Person who } \\
\text { arranged transport }\end{array}$} & ANM & Yes $=1$ & No $=0$ \\
\hline 22. & & Health worker & Yes $=1$ & No $=0$ \\
\hline 23. & & AWW & Yes $=1$ & No $=0$ \\
\hline 24. & & ASHA & Yes $=1$ & No $=0$ \\
\hline 25. & \multicolumn{2}{|c|}{ During pregnancy women received benefits from Anganwadi/ ICDS Centre } & Yes $=1$ & No $=0$ \\
\hline
\end{tabular}




\begin{tabular}{|c|c|c|c|c|}
\hline 26. & \multirow{3}{*}{$\begin{array}{l}\text { Benefits received } \\
\text { during pregnancy } \\
\text { from Anganwadi/ } \\
\text { ICDS Centre }\end{array}$} & supplementary food/ nutrition & Yes $=1$ & No $=0$ \\
\hline 27. & & health check-ups & Yes $=1$ & No $=0$ \\
\hline 28. & & health and nutrition education & Yes $=1$ & No $=0$ \\
\hline 29. & \multicolumn{2}{|c|}{$\begin{array}{l}\text { Child received benefits from Anganwadi/ ICDS Centre in last } 12 \text { months after } \\
\text { birth }\end{array}$} & Yes $=1$ & No $=0$ \\
\hline 30. & \multicolumn{2}{|c|}{$\begin{array}{l}\text { Child received immunization through Anganwadi/ ICDS Centre in last } 12 \\
\text { months after birth }\end{array}$} & Yes $=1$ & No $=0$ \\
\hline 31. & \multirow{4}{*}{$\begin{array}{l}\text { Frequency of } \\
\text { services received } \\
\text { from Anganwadi/ } \\
\text { ICDS Centre, in } \\
\text { last } 12 \text { months after } \\
\text { birth }\end{array}$} & 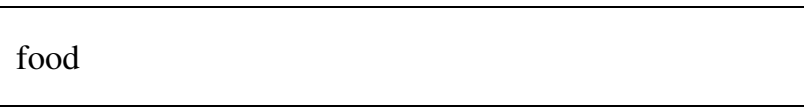 & $\begin{array}{c}\text { almost daily/ } \\
\text { at least once a week } \\
=1\end{array}$ & $\begin{array}{c}\text { Not at all/ } \\
\text { less often/don't kno } \\
=0\end{array}$ \\
\hline 32. & & health check-up & $\begin{array}{l}\text { [at least once a } \\
\text { month] }=1\end{array}$ & $\begin{array}{c}\text { Not at all/ } \\
\text { less often/don't kno } \\
=0\end{array}$ \\
\hline 33. & & childhood care or preschool & $\begin{array}{c}\text { [regularly/occasionally } \\
\text { ] }=1\end{array}$ & {$\left[\begin{array}{c}\text { Not at all } / \\
\text { don't know }\end{array}\right]=0$} \\
\hline 34. & & weight measured & $\begin{array}{c}\text { atleast once a months } \\
\text { at least once in } 3 \text { mont } \\
=1\end{array}$ & $\begin{array}{c}\text { Not at all/ } \\
\text { less often/don't kno } \\
=0\end{array}$ \\
\hline 35 . & \multicolumn{2}{|c|}{$\begin{array}{l}\text { After child weighted, mother received counselling from Anganwadi/ ICDS } \\
\text { Centre }\end{array}$} & Yes $=1$ & $\begin{array}{c}\text { No/ Don't } \\
\text { know }=0\end{array}$ \\
\hline 36. & \multicolumn{2}{|c|}{ While breastfeeding, mother received benefits from Anganwadi/ ICDS Centre } & Yes = 1 & $\begin{array}{c}\text { No/ Didn't } \\
\text { breastfeed }=0\end{array}$ \\
\hline 37. & \multirow{3}{*}{$\begin{array}{l}\text { Benefits received } \\
\text { while breastfeeding } \\
\text { from Anganwadi/ } \\
\text { ICDS Centre }\end{array}$} & supplementary food & Yes $=1$ & No $=0$ \\
\hline 38. & & health check-ups & Yes $=1$ & No $=0$ \\
\hline 39. & & health and nutrition education & Yes $=1$ & No $=0$ \\
\hline 40. & \multicolumn{2}{|c|}{ Place met ANM/ LHV/ ASHA/ AWW/ CHW with pregnant woman } & Home/ Both = 1 & Elsewhere $=0$ \\
\hline 41. & \multirow{7}{*}{ Told about } & $\begin{array}{l}\text { pregnancy complications to the pregnant woman or } \\
\text { family members }\end{array}$ & Yes $=1$ & No $=0$ \\
\hline 42. & & where to go for the pregnancy complications & Yes $=1$ & No $=0$ \\
\hline 43. & & vaginal bleeding & Yes $=1$ & No $=0$ \\
\hline 44. & & convulsions & Yes $=1$ & No $=0$ \\
\hline 45. & & prolonged labour & Yes $=1$ & No $=0$ \\
\hline 46. & & severe abdominal pain & Yes $=1$ & No $=0$ \\
\hline 47. & & high blood pressure & Yes $=1$ & $\mathrm{No}=0$ \\
\hline 48. & \multirow{5}{*}{ Receive advice } & institutional delivery & Yes $=1$ & $\mathrm{No}=0$ \\
\hline 49. & & cord care & Yes $=1$ & $\mathrm{No}=0$ \\
\hline 50. & & breastfeeding & Yes $=1$ & $\mathrm{No}=0$ \\
\hline 51. & & keeping the baby warm & Yes $=1$ & No $=0$ \\
\hline 52. & & family planning & Yes $=1$ & $\mathrm{No}=0$ \\
\hline
\end{tabular}

${ }^{\mathrm{a}}=$ advantageous

${ }^{\mathrm{b}}=$ disadvantageous groups

Additionally, we include several control variables relating to the female respondent and her household's socio-economic and demographic characteristics. These include the child's birth-order, mother's age (categorised into seven discrete age groups), education level (illiterate, primary, secondary, higher, don't know), and occupation (not working/ white collar/ agricultural activities/ service or manual worker/ don't know or missing). Similarly, we include partner's educational level (illiterate, primary, secondary, higher, don't know), partner's occupation (not working/ white collar/ agricultural activities/ service or manual worker/ don't 
know or missing). Other control variables include the respondent's religion (Hindu, Muslim, Christians, Others), Caste (Others, Scheduled Castes [SCs], Scheduled Tribes [STs], Other Backward Classes [OBCs], and Not reported/ Missing), place of residence (rural/urban) and geographical region (North, Central, Eastern, North Eastern, Western and Southern).

Empirical models. We have used two sets of empirical models: (1) Binary Logistic Regression (BLR) models; (2) Cox proportional hazard models along with Kaplan-Meier Plots for showing child survival estimates by FHWEI.

Binary Logistic Regression. Given that four of our outcome variables are binary in nature, we have estimated BLR models for each of four MCH care variables to demonstrate the influence of engagement of FHWE on MCH utilisation measures. The advantage of logistic regression analysis is that it requires no assumption about the distribution of the independent variables, and the regression coefficient can be interpreted in terms of odds ratios. For each of the outcome variables, in addition to the full sample, we have estimated BLR models for two sub-sets of samples: 'poor' women and 'non-poor' women. The same procedure was also followed in robustness checks conducted on samples of 'women delivered in public sector health facilities only' and for women from 'rural areas'. Across all our models we have controlled for an array of respondent's socio-economic and demographic characteristics Table 1. 
Table 1. Descriptive statistics of variables used in the analysis

\begin{tabular}{|c|c|c|c|c|c|c|}
\hline \multirow{3}{*}{ Variables } & \multicolumn{3}{|c|}{ Total samples $(n=259627)$} & \multicolumn{3}{|c|}{$\begin{array}{l}\text { Sample of women delivered at the public } \\
\text { institutions }(n=141028)\end{array}$} \\
\hline & \multirow[b]{2}{*}{$\mathrm{n}$} & $\begin{array}{c}\text { Poor } \\
(n=130132)\end{array}$ & $\begin{array}{c}\text { Non-Poor } \\
(n=129495)\end{array}$ & \multirow[b]{2}{*}{$\mathrm{n}$} & \multirow{2}{*}{$\begin{array}{c}\begin{array}{c}\text { Poor } \\
(n=71446)\end{array} \\
\%(\mathrm{SE})\end{array}$} & \multirow{2}{*}{$\begin{array}{c}\begin{array}{c}\text { Non-Poor } \\
(n=69582)\end{array} \\
\%(\mathrm{SE})\end{array}$} \\
\hline & & $\%\left(\mathrm{SE}^{\mathrm{a}}\right)$ & $\%(\mathrm{SE})$ & & & \\
\hline \multicolumn{7}{|l|}{ Dependent Variables } \\
\hline \multicolumn{7}{|l|}{ ANC Visits } \\
\hline More than 4 & 190898 & $34.8(0.17)$ & $65.8(0.15)$ & 105615 & $40.3(0.23)$ & $64.1(0.21)$ \\
\hline \multicolumn{7}{|l|}{ Place of Delivery } \\
\hline Institutional delivery & 259627 & $66.8(0.14)$ & $89.8(0.08)$ & - & - & - \\
\hline \multicolumn{7}{|l|}{ CFI (12-23 months ago) } \\
\hline Yes & 71422 & $56.8(0.27)$ & $66.2(0.25)$ & 39303 & $62.0(0.35)$ & $67.7(0.36)$ \\
\hline \multicolumn{7}{|l|}{ Infant PNC } \\
\hline Within 2 days & 190898 & $23.1(0.15)$ & $30.3(0.14)$ & 105615 & $26.7(0.20)$ & $31.3(0.21)$ \\
\hline \multicolumn{7}{|l|}{ Child Alive } \\
\hline Yes & 259627 & $94.3(0.07)$ & $96.8(0.05)$ & 141028 & $95.1(0.08)$ & $96.8(0.07)$ \\
\hline \multicolumn{7}{|l|}{ Explanatory variables } \\
\hline \multicolumn{7}{|l|}{ Level of FHWE } \\
\hline Low & 86544 & $34.2(0.13)$ & $29.9(0.12)$ & 36199 & $26.7(0.17)$ & $23.9(0.17)$ \\
\hline Medium & 86607 & $32.4(0.14)$ & $34.0(0.13)$ & 47620 & $33.4(0.18)$ & $32.8(0.19)$ \\
\hline High & 86476 & $33.3(0.14)$ & $36.0(0.13)$ & 57209 & $39.9(0.19)$ & $43.3(0.20)$ \\
\hline \multicolumn{7}{|l|}{ Birth order } \\
\hline 1 & 96212 & $31.0(0.13)$ & $45.4(0.14)$ & 55990 & $35.3(0.19)$ & $44.6(0.19)$ \\
\hline 2 & 79670 & $28.4(0.13)$ & $35.2(0.13)$ & 44600 & $29.5(0.18)$ & $35.9(0.19)$ \\
\hline 3 & 41607 & $18.3(0.11)$ & $12.5(0.09)$ & 21754 & $17.4(0.15)$ & $12.7(0.13)$ \\
\hline $3+$ & 42138 & $22.3(0.12)$ & $06.9(0.07)$ & 18684 & $17.8(0.15)$ & $06.7(0.10)$ \\
\hline \multicolumn{7}{|l|}{ Current age of Women } \\
\hline $15-19$ & 6699 & $3.6(0.05)$ & $02.2(0.04)$ & 4155 & $04.1(0.08)$ & $02.5(0.06)$ \\
\hline $20-24$ & 78177 & $31.9(0.14)$ & $32.3(0.13)$ & 46061 & $34.7(0.19)$ & $35.3(0.19)$ \\
\hline $25-29$ & 99396 & $36.2(0.14)$ & $41.4(0.14)$ & 54319 & $36.5(0.19)$ & $41.1(0.19)$ \\
\hline $30-34$ & 49005 & $17.5(0.11)$ & $17.6(0.10)$ & 24734 & $16.3(0.14)$ & $15.8(0.14)$ \\
\hline $35-39$ & 19212 & $07.6(0.08)$ & $05.5(0.06)$ & 8938 & $6.1(0.09)$ & $04.5(0.08)$ \\
\hline $40-44$ & 5504 & $2.4(0.04)$ & $01.0(0.03)$ & 2242 & $1.7(0.05)$ & $00.7(0.03)$ \\
\hline $45-49$ & 1634 & $00.8(0.03)$ & $00.2(0.01)$ & 579 & $00.6(0.03)$ & $00.1(0.01)$ \\
\hline Educational status of & & & & & & \\
\hline Illiterate & 81087 & $49.7(0.15)$ & $12.4(0.09)$ & 40278 & $43.9(0.19)$ & $12.8(0.13)$ \\
\hline Primary & 37938 & $18.0(0.11)$ & $10.5(0.08)$ & 21176 & $18.5(0.15)$ & $11.7(0.13)$ \\
\hline Secondary & 116646 & $30.7(0.13)$ & $58.6(0.14)$ & 69756 & $35.9(0.19)$ & $63.0(0.19)$ \\
\hline Higher & 23956 & $1.5(0.04)$ & $18.5(0.11)$ & 9818 & $01.7(0.05)$ & $12.4(0.13)$ \\
\hline Husband/ partner's edu & & & & & & \\
\hline Illiterate & 8181 & $5.3(0.06)$ & $01.1(0.03)$ & 3985 & $04.6(0.08)$ & $01.1(0.04)$ \\
\hline Primary & 6587 & $3.4(0.05)$ & $01.7(0.04)$ & 3674 & $03.5(0.07)$ & $01.9(0.05)$ \\
\hline Secondary & 24511 & $7.5(0.08)$ & $11.0(0.09)$ & 14253 & $08.1(0.11)$ & $11.4(0.13)$ \\
\hline Higher & 5783 & $00.5(0.02)$ & $04.1(0.05)$ & 2545 & $00.6(0.03)$ & $02.8(0.06)$ \\
\hline Don't know/missing & 214565 & $83.4(0.10)$ & $82.1(0.10)$ & 116571 & $83.2(0.15)$ & $82.9(0.15)$ \\
\hline Occupation of woman & & & & & & \\
\hline Not working & 34426 & $12.0(0.09)$ & $14.8(0.09)$ & 18750 & $12.3(0.13)$ & $14.1(0.14)$ \\
\hline White collar & 1382 & $00.2(0.01)$ & $00.8(0.02)$ & 678 & $00.2(0.02)$ & $00.6(0.03)$ \\
\hline Agricultural worker & 5974 & $03.1(0.05)$ & $01.2(0.03)$ & 3185 & $02.9(0.06)$ & $01.2(0.04)$ \\
\hline Service/manual work & 3093 & $01.2(0.03)$ & $01.1(0.03)$ & 1742 & $01.2(0.04)$ & $01.1(0.04)$ \\
\hline Don't know/missing & 214752 & $83.5(0.11)$ & $82.2(0.11)$ & 116673 & $83.4(0.15)$ & $82.9(0.15)$ \\
\hline Husband/ partner's occ & & & & & & \\
\hline Not working & 1939 & $00.8(0.03)$ & $00.7(0.02)$ & 1109 & $00.7(0.03)$ & $00.8(0.04)$ \\
\hline White collar & 8945 & $01.6(0.04)$ & $05.5(0.06)$ & 4345 & $01.7(0.05)$ & $04.3(0.08)$ \\
\hline Agricultural worker & 14614 & $06.9(0.07)$ & $03.6(0.05)$ & 7992 & $06.9(0.09)$ & $03.9(0.07)$ \\
\hline Service/manual work & 19161 & $07.0(0.07)$ & $07.9(0.07)$ & 10803 & $07.2(0.10)$ & $07.9(0.11)$ \\
\hline Don't know/missing & 214968 & $83.6(0.11)$ & $82.2(0.10)$ & 116779 & $83.4(0.14)$ & $83.0(0.15)$ \\
\hline Caste & & & & & & \\
\hline Others & 45019 & $11.9(0.09)$ & $26.2(0.12)$ & 22160 & $11.1(0.12)$ & $22.3(0.16)$ \\
\hline $\mathrm{SC}$ & 49051 & $25.6(0.13)$ & $17.9(0.11)$ & 29879 & $27.5(0.17)$ & $22.0(0.16)$ \\
\hline
\end{tabular}




\begin{tabular}{|c|c|c|c|c|c|c|}
\hline ST & 52199 & $16.5(0.11)$ & $5.2(0.06)$ & 27546 & $16.5(0.14)$ & $05.9(0.09)$ \\
\hline OBC & 101786 & $41.6(0.14)$ & $46.5(0.14)$ & 54436 & $40.7(0.19)$ & $44.8(0.19)$ \\
\hline Don't know/not reported & 11572 & $4.3(0.05)$ & $04.4(0.06)$ & 7007 & $04.2(0.08)$ & $04.9(0.09)$ \\
\hline \multicolumn{7}{|l|}{ Religion } \\
\hline Hindus & 187573 & $80.6(0.12)$ & $76.9(0.12)$ & 106876 & $84.6(0.14)$ & $78.5(0.16)$ \\
\hline Muslims & 40950 & $16.0(0.11)$ & $17.0(0.10)$ & 19441 & $12.6(0.13)$ & $15.3(0.14)$ \\
\hline Christians & 20934 & $1.6(0.04)$ & $02.5(0.03)$ & 9279 & $01.2(0.04)$ & $02.2(0.06)$ \\
\hline Others & 10170 & $1.8(0.04)$ & $03.6(0.05)$ & 5432 & $01.6(0.05)$ & $03.9(0.08)$ \\
\hline \multicolumn{7}{|l|}{ Place of residence } \\
\hline Rural & 198248 & $91.9(0.08)$ & $54.0(0.14)$ & 110259 & $91.4(0.11)$ & $58.4(0.19)$ \\
\hline Urban & 61379 & $08.1(0.08)$ & $45.9(0.14)$ & 30769 & $08.6(0.11)$ & $41.6(0.19)$ \\
\hline \multicolumn{7}{|l|}{ Region } \\
\hline Northern & 48703 & $07.6(0.08)$ & $18.2(0.11)$ & 29692 & $08 .(0.11)$ & $21.5(0.16)$ \\
\hline Central & 75645 & $33.1(0.14)$ & $21.8(0.11)$ & 40356 & $32.7(0.18)$ & $21.1(0.16)$ \\
\hline Eastern & 54075 & $39.0(0.14)$ & $13.5(0.09)$ & 29373 & $37.4(0.19)$ & $14.0(0.14)$ \\
\hline North-eastern & 37167 & $04.8(0.06)$ & $02.4(0.04)$ & 18861 & $04.7(0.08)$ & $02.9(0.07)$ \\
\hline Western & 18276 & $07.8(0.08)$ & $17.2(0.10)$ & 8061 & $07.5(0.01)$ & $13.9(0.14)$ \\
\hline Southern & 25761 & $07.6(0.08)$ & $27.3(0.12)$ & 14685 & $09.3(0.11)$ & $26.5(0.17)$ \\
\hline
\end{tabular}

${ }^{a}$ SE represents Standard Error.

Below we have explained the BLR model using 4+ ANC visits as an outcome variable. For example, we could define $4+$ ANC visits as:

$y_{i}\left\{\begin{array}{lc}1 & \text { if the } i \text { th woman has made } 4+\text { ANC visits } \\ 0 & \text { otherwise }\end{array}\right\}$

As in [49] Retherford and Choe, (1993), for the above binary dependent variables $\left(y_{i}\right)$, the BLR model takes the following general form:

$\log \left(\frac{\mathrm{P}_{4+\mathrm{ANC} \text { visits }}}{1-\mathrm{P}_{4+\mathrm{ANC} \text { visits }}}\right)=\operatorname{Logit}\left(\mathrm{P}_{4+\mathrm{ANC} \text { visits }}\right)=\mathrm{b}_{0}+\mathrm{b}_{1} \mathrm{X}_{1}=\mathrm{FHWE}+\mathrm{b}_{2} \mathrm{X}_{2}+\mathrm{b}_{3} \mathrm{X}_{3}+\ldots . . \mathrm{b}_{\mathrm{k}} \mathrm{Xk}_{\mathrm{k}}+\mathrm{e}_{\mathrm{k}}$

$\mathrm{P}_{4+\mathrm{ANC}}$ visits is the probability of making $4+\mathrm{ANC}$ visits, $\mathrm{b}_{0}$ is the $y$ intercept, and $\mathrm{X}_{1=\mathrm{FHWE}}$ is the level of female respondent's engagement with a FHW, and the term $\mathrm{b}_{1} \mathrm{x}_{1}$ is the regression coefficient $\mathrm{X}_{1=\mathrm{FHWE}}$

Cox proportion hazard regression model. Next, a Cox proportional hazard model is used to estimate the relationship between FHW's engagement with mothers and under-five child survival. It is a semi-parametric model which is used in 'time-to-event' data with censoring and covariates. The model has used only the rank order of the failure and the censoring times, 
which is less influenced by the outliers in the failure times [50,51]. The general form of the model is given as [52]:

$\left.\mathrm{h}_{\mathrm{i}}(\mathrm{t}, \mathrm{X})=\mathrm{h}_{0}(\mathrm{t}) \exp \left\{\beta^{*} \mathrm{X}(\mathrm{FHWE})\right\}=\mathrm{h}_{0}(\mathrm{t}) \exp \left\{\sum_{\mathrm{i}=1}^{\mathrm{p}} \beta_{\mathrm{i}} \mathrm{X}_{\mathrm{FHWE}}+\beta_{2} X_{2}+\ldots+\beta_{k} X_{k}\right)\right\}$

Where,

$t$ represents the survival time, $h_{i}(t, X)$ is the hazard function determined by $X_{1=F H W E}$ and controlled for covariates $(\mathrm{x} 2, \ldots, \mathrm{xk})$, and the coefficients $\left(\beta_{1}, \beta_{2}, \ldots, \beta_{\mathrm{k}}\right)$ measure the impact (i.e., the effect size) of covariates.

The term $\mathrm{h}_{0}(\mathrm{t})$ is called the baseline hazard. It corresponds to the value of the hazard if all the $\mathrm{X}_{i}$ are equal to zero (the quantity $\exp (0)$ equals 1 ). The ' $\mathrm{t}$ ' in $\mathrm{h}(\mathrm{t})$ reminds us that the hazard may vary over time [32] (Hyeoun-Ae, 2013).

\section{Results}

\section{Descriptive statistics}

Table 1 presents the descriptive statistics for all the variables used in this study, disaggregated by the household's economic status (poor and non-poor). The household's economic status is based on the wealth index that is available in the NFHS dataset, where households are classified into five wealth quintiles, constructed using assets owned by households and applying principal components analysis [3]. We classify the first two categories (poorest and poor households) as being in the category 'poor', and classify households in the middle, rich and richest as being 'non-poor' $[11,53]$.

From the descriptive statistics for the full sample presented in Table 1, we observe that across all our five outcome variables, women from non-poor households have better MCH care and child health outcomes. Women from non-poor households received relatively better ANC care. In particular, $65.8 \%$ had $4+$ antenatal visits, in comparison to $34.8 \%$ for women from poor 
households. Approximately, $89.8 \%$ of women from non-poor households gave birth at health facilities relative to $66.8 \%$ among women from poor households, and their children also received more full immunisation (66.2\% compared to $56.6 \%$ for poor women). Furthermore, although postnatal care of children was generally low in the sample, a higher proportion of children from non-poor households were PNC (30.3\%) relative to children from poor households (23.1\%). We also observe that there were fewer under-five child deaths $(3.2 \%)$ in the non-poor sample relative to $5.7 \%$ among poor women. Further, engagement with FHWs was also greater among married women from non-poor households (36\%) relative to women from poor-households (33.3\%). Women with higher-order births (3 or more children) are more likely to be present in poor households $(22.3 \%)$ compared to $6.9 \%$ among non-poor households. However, in the sample of women who gave birth in public institutions, the economic differences in $\mathrm{MCH}$ care and outcome indicators and engagement with FHWs is slightly lower.

The sample distribution for other background characteristics by the economic status of women who delivered in all facilities and public institutions are as expected. In India, caste is considered to be an important marker of social disadvantage, and the Indian government has introduced a policy of affirmative action, for individuals from social and economic backward castes and tribes (called Scheduled Castes (SCs), STs, and Other Backward Castes (OBCs)). Among the poor, $41.6 \%$ of the sample are from OBCs, $25.6 \%$ are from SCs, and $16.5 \%$ are from STs and $16.3 \%$ are from others. This distribution is $46.5 \%, 17.9 \%, 9.4 \%$ and $26.2 \%$ respectively among the non-poor. In terms of religion, majority of to the sample are Hindus (poor: $80.6 \%$, non-poor: $76.9 \%$ ) followed by Muslims (poor: 16.0\%, non-poor:17.05\%). About $91.9 \%$ of poor and $54 \%$ of non-poor women live in rural areas.

\section{Association between FHWE and MCH services}


Table 2 shows unadjusted and adjusted estimates of odds ratios from the BLR model. The adjusted estimates show the association between the MCH services and the level of FHWE for the disaggregate samples of poor and non-poor women controlling for an array of sociodemographic characteristics. The unadjusted results show that among economically poor women having higher engagement with FHWs are 8.02 times $(\mathrm{p}<0.05)$ more likely to access 4 and more ANC visits, relative to those with low FHW engagement. Similarly, among females from poor households, the likelihood of institutional delivery is 2.80 times $(\mathrm{p}<0.05)$ greater for women with higher FHW engagement than for those with low FHW engagement. Furthermore, among poor households, having a high level of engagement with maternal engagement with FHWs is associated with 2.88 times $(\mathrm{p}<0.01)$ higher likelihood of CFI and 4.65 times $(\mathrm{p}<0.05)$ higher likelihood of PNC (within 2 days of delivery), compared to women with those who have low-level of FHWE. Although the influence of FHW engagement on $\mathrm{MCH}$ services among non-poor women is slightly low compared to poor women, within the sample of non-poor women, the utilisation of $\mathrm{MCH}$ services is almost two times higher among those with higher FHW engagement compared to their counterparts. Differences in $\mathrm{MCH}$ services by the level of FHW engagement do not change in adjusted estimates in both the poor and non-poor samples. 


\begin{tabular}{|c|c|c|c|c|c|c|c|c|c|c|c|c|}
\hline \multirow[b]{2}{*}{ Predictor Variables } & \multicolumn{3}{|c|}{$\frac{\text { Antenatal Care }(4 \text { or }>4 \text { times })}{\text { Odds Ratio }\left(\mathrm{SE}^{\mathrm{a}}\right)}$} & \multicolumn{3}{|c|}{$\frac{\text { Place of delivery (All Institutions) }}{\text { Odds Ratio (SE) }}$} & \multicolumn{3}{|c|}{$\begin{array}{c}\text { Child full immunization (12-23 months) } \\
\text { Odds Ratio (SE) }\end{array}$} & \multicolumn{3}{|c|}{$\begin{array}{c}\text { Infant Postnatal care (within } 2 \text { days of delivery) } \\
\text { Odds Ratio (SE) }\end{array}$} \\
\hline & $\begin{array}{c}\text { Poor } \\
(n=90521)\end{array}$ & $\begin{array}{l}\text { Non-Poor } \\
(n=100377)\end{array}$ & $\begin{array}{c}\text { Total } \\
(\mathrm{n}=190898)\end{array}$ & $\begin{array}{c}\text { Poor } \\
(n=130132)\end{array}$ & $\begin{array}{l}\text { Non-Poor } \\
(n=129495)\end{array}$ & $\begin{array}{c}\text { Total } \\
(n=259627)\end{array}$ & $\begin{array}{c}\text { Poor } \\
(n=36995)\end{array}$ & $\begin{array}{l}\text { Non-Poor } \\
(n=34427)\end{array}$ & $\begin{array}{c}\text { Total } \\
(n=71422)\end{array}$ & $\begin{array}{c}\text { Poor } \\
(n=90521)\end{array}$ & $\begin{array}{l}\text { Non-Poor } \\
(n=100377)\end{array}$ & $\begin{array}{c}\text { Total } \\
(n=190898)\end{array}$ \\
\hline \multicolumn{13}{|c|}{ Panel A (Unadjusted) } \\
\hline \multicolumn{13}{|c|}{ Level of FHWE } \\
\hline \multicolumn{13}{|l|}{ Low } \\
\hline Medium & $2.448^{*}(0.06)$ & $1.704^{*}(0.03)$ & $1.855^{*}(0.02)$ & $1.805^{*}(0.03)$ & $1.729^{*}(0.04)$ & $1.801^{*}(0.02)$ & $1.784^{*}(0.05)$ & $\left.1.444^{*} 0.04\right)$ & $1.627^{*}(0.03)$ & $\left.1.971^{*} 0.06\right)$ & $1.554^{*}(0.03)$ & $1.723^{*}(0.03)$ \\
\hline High & $8.023^{*}(0.18)$ & $2.297^{*}(0.04)$ & $3.375^{*}(0.04)$ & $2.803^{*}(0.04)$ & $2.684^{*}(0.06)$ & $2.746^{*}(0.03)$ & $2.882^{*}(0.08)$ & $\left.2.109^{*} 0.06\right)$ & $2.505^{*}(0.05)$ & $\left.4.647^{*} 0.11\right)$ & $2.713^{*}(0.05)$ & $3.334^{*}(0.05)$ \\
\hline \multicolumn{13}{|c|}{ Panel B (Adjusted) } \\
\hline \multicolumn{13}{|l|}{ Level of FHWE } \\
\hline \multicolumn{13}{|l|}{ Low } \\
\hline Medium & $2.174^{*}(0.05)$ & $1.766^{*}(0.03)$ & $1.771^{*}(0.03)$ & $1.678^{*}(0.03)$ & $1.616^{*}(0.04)$ & $1.659^{*}(0.02)$ & $1.717^{*}(0.05)$ & $1.429^{*}(0.04)$ & $1.586^{*}(0.03)$ & $\left.1.95^{* * *} 0.06\right)$ & $1.567^{*}(0.03)$ & $1.706^{*}(0.03)$ \\
\hline High & $6.367^{*}(0.16)$ & $2.489^{*}(0.04)$ & $3.305^{*}(0.05)$ & $2.538^{*}(0.04)$ & $2.543^{*}(0.07)$ & $2.531^{*}(0.03)$ & $2.692^{*}(0.08)$ & $2.067^{*}(0.06)$ & $2.406^{*}(0.05)$ & $\left.4.63^{* * * *} 0.12\right)$ & $2.876^{*}(0.05)$ & $3.480^{*}(0.05)$ \\
\hline \multicolumn{13}{|l|}{ Birth Order } \\
\hline \multicolumn{13}{|l|}{1} \\
\hline 2 & $0.747^{*}(0.02)$ & $0.777^{*}(0.01)$ & $-0.277^{*}(0.01)$ & $0.582^{*}(0.01)$ & $0.519^{*}(0.01)$ & $0.554^{*}(0.01)$ & $0.827^{*}(0.03)$ & $0.871^{*}(0.02)$ & $0.846^{*}(0.02)$ & $0.965(0.02)$ & $0.958^{*}(0.02)$ & $0.957^{*}(0.01)$ \\
\hline 3 & $0.588^{*}(0.02)$ & $0.597^{*}(0.01)$ & $-0.557^{*}(0.02)$ & $0.464^{*}(0.01)$ & $0.356^{*}(0.01)$ & $0.411^{*}(0.01)$ & $0.769^{*}(0.03)$ & $0.696^{*}(0.03)$ & $0.729^{*}(0.02)$ & $0.911^{*}(0.02)$ & $0.949^{*}(0.02)$ & $0.918^{*}(0.02)$ \\
\hline $3+$ & $0.426^{*}(0.01)$ & $0.421^{*}(0.01)$ & $-0.962^{*}(0.02)$ & $0.389^{*}(0.01)$ & $0.273^{*}(0.01)$ & $0.328^{*}(0.01)$ & $0.718^{*}(0.03)$ & $0.622^{*}(0.03)$ & $0.653^{*}(0.02)$ & $0.952(0.03)$ & $0.881^{*}(0.03)$ & $0.874^{*}(0.02)$ \\
\hline \multicolumn{13}{|c|}{ Current age of woman } \\
\hline \multicolumn{13}{|c|}{\begin{tabular}{l|l}
$15-19$ &
\end{tabular}} \\
\hline $20-24$ & $0.955(0.04)$ & $1.054(0.05)$ & $0.026(0.03)$ & $0.969(0.04)$ & $0.909(0.06)$ & $0.999(0.04)$ & $1.088(0.07)$ & $1.009(0.08)$ & $1.066(0.05)$ & $1.074(0.05)$ & $0.959(0.02)$ & $1.039(0.03)$ \\
\hline $25-29$ & $1.043(0.04)$ & $1.302^{*}(0.06)$ & $0.221^{*}(0.03)$ & $1.042(0.04)$ & $1.113(0.09)$ & $1.164^{*}(0.04)$ & $1.159^{*}(0.07)$ & $1.152^{*}(0.09)$ & $1.186^{*}(0.06)$ & $1.119^{*}(0.05)$ & $0.999(0.02)$ & $1.098^{*}(0.04)$ \\
\hline $30-34$ & $1.143^{*}(0.05)$ & $1.606^{*}(0.08)$ & $0.409^{*}(0.03)$ & $1.135^{*}(0.05)$ & $1.577^{*}(0.13)$ & $1.416^{*}(0.06)$ & $1.159^{*}(0.08)$ & $1.249^{*}(0.11)$ & $1.246^{*}(0.07)$ & $1.119^{*}(0.06)$ & $1.008(0.05)$ & $1.117^{*}(0.04)$ \\
\hline $35-39$ & $1.195^{*}(0.06)$ & $1.720^{*}(0.09)$ & $0.454^{*}(0.04)$ & $1.004(0.05)$ & $1.764^{*}(0.16)$ & $1.326^{*}(0.06)$ & $1.090(0.09)$ & $1.577^{*}(0.16)$ & $1.314^{*}(0.08)$ & $1.144^{*}(0.06)$ & $1.198^{*}(0.07)$ & $1.239^{*}(0.05)$ \\
\hline $40-44$ & $1.097(0.08)$ & $1.641^{*}(0.13)$ & $0.355^{*}(0.05)$ & $0.898^{*}(0.05)$ & $1.346^{*}(0.15)$ & $1.130^{*}(0.06)$ & $1.109(0.13)$ & $1.385^{*}(0.25)$ & $1.264^{*}(0.12)$ & $1.141^{*}(0.08)$ & $1.189^{*}(0.09)$ & $1.198^{*}(0.06)$ \\
\hline $45-49$ & $0.931(0.11)$ & $1.369^{*}(0.22)$ & $0.159^{*}(0.09)$ & $0.758^{*}(0.06)$ & $0.929(0.16)$ & $0.918(0.07)$ & $1.380^{*}(0.23)$ & $1.156(0.50)$ & $1.403^{*}(0.22)$ & $0.911(0.10)$ & $1.218(0.19)$ & $0.999(0.09)$ \\
\hline \multicolumn{13}{|c|}{ Education status of women } \\
\hline \multicolumn{13}{|c|}{\begin{tabular}{l|l} 
Illiterate & \\
\end{tabular}} \\
\hline Primary & $1.556^{*}(0.04)$ & $1.290^{*}(0.04)$ & $0.453^{*}(0.02)$ & $1.252^{*}(0.02)$ & $1.194^{*}(0.04)$ & $1.272^{*}(0.02)$ & $1.269^{*}(0.04)$ & $1.317^{*}(0.06)$ & $1.336^{*}(0.03)$ & $1.082^{*}(0.03)$ & $1.069^{*}(0.04)$ & $1.123^{*}(0.02)$ \\
\hline Secondary & $1.724^{*}(0.04)$ & $1.713^{*}(0.04)$ & $0.741^{*}(0.01)$ & $1.837^{*}(0.03)$ & $2.133^{*}(0.05)$ & $2.263^{*}(0.03)$ & $1.443^{*}(0.04)$ & $1.513^{*}(0.06)$ & $1.604^{*}(0.03)$ & $1.061^{*}(0.02)$ & $1.171^{*}(0.03)$ & $1.221^{*}(0.02)$ \\
\hline Higher & $2.146^{*}(0.14)$ & $2.357^{*}(0.07)$ & $1.145^{*}(0.02)$ & $3.203^{*}(0.24)$ & $4.685^{*}(0.21)$ & $5.587^{*}(0.20)$ & $1.557^{*}(0.15)$ & $1.736^{*}(0.08)$ & $1.908^{*}(0.07)$ & $1.152^{*}(0.08)$ & $1.333^{*}(0.04)$ & $1.447^{*}(0.03)$ \\
\hline \multicolumn{13}{|c|}{ Education status of husband/partner } \\
\hline Illiterate & & & & & & & & & & & & \\
\hline Primary & $1.044(0.06)$ & $1.135(0.09)$ & $0.106^{*}(0.05)$ & $1.132^{*}(0.05)$ & $0.939(0.09)$ & $1.077^{*}(0.04)$ & $1.121(0.09)$ & $0.983(0.13)$ & $1.056(0.07)$ & $1.067(0.06)$ & $1.001(0.09)$ & $1.052(0.05)$ \\
\hline Secondary & $1.077(0.05)$ & $1.186^{*}(0.09)$ & $0.192^{*}(0.04)$ & $1.272^{*}(0.05)$ & $1.324^{*}(0.10)$ & $1.331^{*}(0.04)$ & $1.206^{*}(0.08)$ & $1.372^{*}(0.15)$ & $1.288^{*}(0.07)$ & $1.019(0.05)$ & $1.057(0.08)$ & $1.076^{*}(0.04)$ \\
\hline Higher & $1.038(0.12)$ & $1.314^{*}(0.11)$ & $0.343^{*}(0.05)$ & $1.593^{*}(0.19)$ & $1.689^{*}(0.17)$ & $1.803^{*}(0.12)$ & $1.173(0.21)$ & $1.166(01.4)$ & $1.168^{*}(0.09)$ & $1.030(0.13)$ & $0.975(0.08)$ & $1.017(0.05)$ \\
\hline $\begin{array}{l}\text { Don't } \\
\text { Know/missing }\end{array}$ & $1.061(0.23)$ & $1.077(0.23)$ & $0.129(0.15)$ & $1.230(0.21)$ & $2.185^{*}(0.58)$ & $1.565^{*}(0.22)$ & $1.209(0.39)$ & $1.289(0.45)$ & $1.239(0.29)$ & $1.073(0.24)$ & $0.922(0.19)$ & $1.013(0.16)$ \\
\hline
\end{tabular}




\begin{tabular}{|c|c|c|c|c|c|c|c|c|c|c|c|c|}
\hline Not working & & & & & & & & & & & & \\
\hline White collar & $0.686^{*}(0.14)$ & $0.771^{*}(0.07)$ & $-0.281^{*}(0.08)$ & $1.089(0.19)$ & $1.013(0.17)$ & $1.076(0.13)$ & $3.159^{*}(1.09)$ & $1.085(0.17)$ & $1.323^{*}(0.19)$ & $1.258(0.24)$ & $1.111^{*}(0.09)$ & $1.119^{*}(0.08)$ \\
\hline Agricultural worker & $0.919(0.05)$ & $1.107(0.08)$ & $-0.031(0.04)$ & $0.857^{*}(0.04)$ & $0.712^{*}(0.06)$ & $0.816^{*}(0.03)$ & $0.946(0.07)$ & $1.116(0.13)$ & $0.970(0.06)$ & $1.113^{*}(0.06)$ & $\left.1.226^{*} 0.08\right)$ & $1.147^{*}(0.05)$ \\
\hline $\begin{array}{l}\text { Service/manual } \\
\text { work }\end{array}$ & $1.130(0.09)$ & $1.020(0.07)$ & $-0.066(0.05)$ & $0.810^{*}(0.05)$ & $0.691^{*}(0.06)$ & $0.771^{*}(0.04)$ & $1.322^{*}(0.15)$ & $0.845(0.10)$ & $1.047(0.09)$ & $1.205^{*}(0.09)$ & $1.124^{*}(0.07)$ & $1.156^{*}(0.06)$ \\
\hline $\begin{array}{l}\text { Don't } \\
\text { know/missing }\end{array}$ & $0.996(0.17)$ & $0.752(0.13)$ & $-0.159(0.12)$ & $0.801^{*}(0.11)$ & $0.581^{*}(0.13)$ & $0.695^{*}(0.08)$ & $1.045(0.28)$ & $1.052(0.03)$ & $1.051(0.19)$ & $1.245(0.22)$ & $1.311(0.22)$ & $1.277^{*}(0.15)$ \\
\hline \multicolumn{13}{|c|}{ Occupational status of husband/partner } \\
\hline \multicolumn{13}{|c|}{\begin{tabular}{l|l|l} 
Not working & & \\
\end{tabular}} \\
\hline White collar & $0.980(0.12)$ & $1.137(0.09)$ & $0.129^{*}(0.07)$ & $1.052(0.09)$ & $0.956(0.13)$ & $1.091(0.08)$ & $0.959(0.16)$ & $1.447^{*}(0.20)$ & $1.255^{*}(0.13)$ & $1.289^{*}(0.16)$ & $1.068(0.09)$ & $1.149^{*}(0.08)$ \\
\hline Agricultural worker & $1.003(0.11)$ & $0.933(0.08)$ & $-0.017(0.07)$ & $0.956(0.08)$ & $0.859(0.11)$ & $0.910(0.06)$ & $1.042(0.15)$ & $1.099(0.16)$ & $1.091(0.12)$ & $1.027(0.11)$ & $0.923(0.08)$ & $0.961(0.07)$ \\
\hline $\begin{array}{l}\text { Service/manual } \\
\text { work }\end{array}$ & $1.092(0.11)$ & $1.227^{*}(0.11)$ & $0.163^{*}(0.07)$ & $1.128(0.09)$ & $0.891(0.11)$ & $1.053(0.07)$ & $1.232(0.18)$ & $1.614^{*}(0.22)$ & $1.406^{*}(0.14)$ & $1.320^{*}(0.15)$ & $1.166^{*}(0.09)$ & $1.221^{*}(0.08)$ \\
\hline $\begin{array}{l}\text { Don't } \\
\text { know/missing }\end{array}$ & $0.984(0.20)$ & $1.427^{*}(0.25)$ & $0.188(0.13)$ & $1.143(0.17)$ & $0.825(0.19)$ & $1.042(0.13)$ & $0.947(0.25)$ & $1.129(0.32)$ & $1.029(0.20)$ & $0.937(0.22)$ & $0.919(0.16)$ & $0.923(0.13)$ \\
\hline \multicolumn{13}{|l|}{ Caste } \\
\hline \multicolumn{13}{|l|}{ Others } \\
\hline SC & $0.723^{*}(0.02)$ & $0.839^{*}(0.02)$ & $-0.306^{*}(0.02)$ & $0.973(0.02)$ & $0.737^{*}(0.02)$ & $0.816^{*}(0.02)$ & $0.958(0.04)$ & $1.043(0.04)$ & $0.982(0.03)$ & $1.069^{*}(0.03)$ & $0.998(0.02)$ & $0.969^{*}(0.02)$ \\
\hline ST & $0.807^{*}(0.03)$ & $0.781^{*}(0.03)$ & $-0.259^{*}(0.02)$ & $0.629^{*}(0.02)$ & $0.488^{*}(0.02)$ & $0.517^{*}(0.01)$ & $0.754^{*}(0.04)$ & $0.985(0.06)$ & $0.793^{*}(0.03)$ & $1.096^{*}(0.04)$ & $0.906^{*}(0.03)$ & $0.954^{*}(0.02)$ \\
\hline $\mathrm{OBC}$ & $0.626^{*}(0.02)$ & $0.769^{*}(0.01)$ & $-0.377^{*}(0.02)$ & $1.075^{*}(0.02)$ & $0.884^{*}(0.02)$ & $0.948^{*}(0.02)$ & $0.939(0.04)$ & $1.058^{*}(0.03)$ & $0.992(0.02)$ & $1.077^{*}(0.03)$ & $0.966^{*}(0.02)$ & $0.972^{*}(0.01)$ \\
\hline $\begin{array}{l}\text { Don't } \\
\text { know/missing }\end{array}$ & $1.101^{*}(0.05)$ & $1.029(0.04)$ & $0.029(0.03)$ & $0.874^{*}(0.03)$ & $1.171^{*}(0.06)$ & $0.899^{*}(0.03)$ & $1.013(0.07)$ & $1.130^{*}(0.07)$ & $1.052(0.04)$ & $0.867^{*}(0.04)$ & $0.800^{*}(0.03)$ & $0.805^{*}(0.02)$ \\
\hline \multicolumn{13}{|l|}{ Religion } \\
\hline \multicolumn{13}{|l|}{ Hindus } \\
\hline Muslims & $1.048^{*}(0.03)$ & $1.140^{*}(0.02)$ & $0.118^{*}(0.02)$ & $0.556^{*}(0.01)$ & $0.660^{*}(0.02)$ & $0.591^{*}(0.01)$ & $\left.0.804^{*} 0.03\right)$ & $0.839^{*}(0.03)$ & $0.829^{*}(0.02)$ & $1.016(0.03)$ & $1.148^{*}(0.02)$ & $1.105^{*}(0.02)$ \\
\hline Christians & $1.057(0.07)$ & $0.885^{*}(0.04)$ & $-0.013(0.04)$ & $0.589^{*}(0.03)$ & $0.919(0.08)$ & $0.770^{*}(0.03)$ & $1.198^{*}(0.12)$ & $1.099(0.09)$ & $1.169^{*}(0.07)$ & $0.908(0.06)$ & $1.039(0.05)$ & $1.007(0.04)$ \\
\hline Others & $1.429^{*}(0.08)$ & $1.391^{*}(0.06)$ & $0.347^{*}(0.03)$ & $0.574^{*}(0.03)$ & $1.287^{*}(0.08)$ & $0.814^{*}(0.03)$ & $1.358^{*}(0.12)$ & $1.741^{*}(0.13)$ & $1.620^{*}(0.09)$ & $1.125^{*}(0.07)$ & $1.490^{*}(0.05)$ & $1.404^{*}(0.04)$ \\
\hline \multicolumn{13}{|l|}{ Place of residence } \\
\hline Rural & & & & & & & & & & & & \\
\hline Urban & $1.576^{*}(0.05)$ & $1.451^{*}(0.02)$ & $0.607^{*}(0.01)$ & $1.243^{*}(0.03)$ & $1.375^{*}(0.02)$ & $1.611^{*}(0.02)$ & $1.064(0.05)$ & $0.957^{*}(0.02)$ & $1.085^{*}(0.02)$ & $1.096^{*}(0.03)$ & $1.057^{*}(0.02)$ & $1.164^{*}(0.01)$ \\
\hline \multicolumn{13}{|l|}{ Region } \\
\hline \multicolumn{13}{|l|}{ Northern } \\
\hline Central & $0.551^{*}(0.02)$ & $0.694^{*}(0.02)$ & $-0.544^{*}(0.02)$ & $0.553^{*}(0.02)$ & $0.663^{*}(0.02)$ & $0.574^{*}(0.01)$ & $0.937(0.04)$ & $0.789^{*}(0.03)$ & $0.776^{*}(0.02)$ & $1.064^{*}(0.04)$ & $1.221^{*}(0.03)$ & $1.073^{*}(0.02)$ \\
\hline Eastern & $0.829^{*}(0.03)$ & $1.157^{*}(0.03)$ & $-0.186^{*}(0.02)$ & $0.484^{*}(0.01)$ & $0.823^{*}(0.03)$ & $0.512^{*}(0.01)$ & $1.734^{*}(0.08)$ & $1.356^{*}(0.06)$ & $1.361^{*}(0.04)$ & $0.870^{*}(0.03)$ & $0.885^{*}(0.02)$ & $0.794^{*}(0.02)$ \\
\hline North-eastern & $0.946^{*}(0.04)$ & $1.313^{*}(0.06)$ & $-0.056^{*}(0.03)$ & $0.471^{*}(0.02)$ & $0.796^{*}(0.05)$ & $0.483^{*}(0.02)$ & $0.740^{*}(0.05)$ & $0.634^{*}(0.05)$ & $0.611^{*}(0.03)$ & $0.976(0.05)$ & $0.712^{*}(0.04)$ & $0.762^{*}(0.03)$ \\
\hline Western & $2.299^{*}(0.09)$ & $2.265^{*}(0.06)$ & $0.765^{*}(0.02)$ & $0.952^{*}(0.03)$ & $2.083^{*}(0.08)$ & $1.339^{*}(0.03)$ & $0.731^{*}(0.04)$ & $0.544^{*}(0.02)$ & $0.579^{*}(0.02)$ & $1.157^{*}(0.05)$ & $0.841^{*}(0.20)$ & $0.881^{*}(0.02)$ \\
\hline Southern & $3.451^{*}(0.15)$ & $2.780^{*}(0.06)$ & $1.041^{*}(0.02)$ & $1.448^{*}(0.06)$ & $3.395^{*}(0.13)$ & $2.319^{*}(0.07)$ & $1.118^{*}(0.07)$ & $0.807^{*}(0.03)$ & $0.869^{*}(0.03)$ & $1.003(0.04)$ & $0.982(0.02)$ & $0.959^{*}(0.02)$ \\
\hline
\end{tabular}

${ }^{a}$ SE represents Standard Error in the parentheses; ${ }^{*} p<0.05$; FHWE: Frontline Health Worker Interaction; CFI: Child Full Immunization. 
Table 3 presents the unadjusted and adjusted hazard ratio (HR) from the Cox proportionalhazards regression model. The results show that relative to those with a low level of engagement with FHWs, a high level of engagement with FHWs reduces the relative risk of under-five child deaths by about five times $(H R=0.220, \mathrm{p}<0.01)$ for poor women and by four times $(\mathrm{p}<0.01)$ for non-poor women. These results are in line with the Kaplan-Meier's survival estimates. The Kaplan-Meier's probability of survival plots suggests significant survival differences by the level of FHW engagement among the samples of both poor and non-poor women. However, it is notable that engagement with FHWs is making a slightly greater difference in child survival times for poor women relative to non-poor women. In other words, poor women benefit relatively more from engagement with FHW than non-poor women (Fig 1).

Fig 1. Kaplan-Meier child survival estimates by level of mother's FHWE among the poor and non-poor households in India, 2015-16. (TIFF).

\begin{tabular}{|c|c|c|c|}
\hline \multirow{2}{*}{ Predictor Variables } & \multicolumn{3}{|c|}{ Hazard Ratio $\left(\mathrm{SE}^{\mathrm{a}}\right)$} \\
\hline & Poor $(n=130132)$ & Non-Poor $(n=129495)$ & Total $(n=259627)$ \\
\hline \multicolumn{4}{|l|}{ Panel A (Unadjusted) } \\
\hline \multicolumn{4}{|l|}{ Level of FHWE } \\
\hline \multicolumn{4}{|l|}{ Low } \\
\hline Medium & $0.569^{*}(0.02)$ & $0.589^{*}(0.03)$ & $0.561^{*}(0.02)$ \\
\hline High & $0.220^{*}(0.01)$ & $0.254^{*}(0.02)$ & $0.227^{*}(0.01)$ \\
\hline \multicolumn{4}{|l|}{ Panel B (Adjusted) } \\
\hline \multicolumn{4}{|l|}{ Level of FHWE } \\
\hline \multicolumn{4}{|l|}{ Low } \\
\hline Medium & $0.572^{*}(0.03)$ & $0.599^{*}(0.03)$ & $0.585^{*}(0.02)$ \\
\hline High & $0.223^{*}(0.01)$ & $0.251^{*}(0.02)$ & $0.236^{*}(0.01)$ \\
\hline \multicolumn{4}{|l|}{ Birth Order } \\
\hline \multicolumn{4}{|l|}{1} \\
\hline 2 & $0.937(0.06)$ & $1.187^{*}(0.08)$ & $1.045(0.05)$ \\
\hline 3 & $1.091(0.07)$ & $1.389^{*}(0.12)$ & $1.233^{*}(0.06)$ \\
\hline $3+$ & $1.318^{*}(0.09)$ & $2.433^{*}(0.23)$ & $1.657^{*}(0.09)$ \\
\hline \multicolumn{4}{|c|}{ Current age of woman } \\
\hline \multicolumn{4}{|c|}{$15-19$} \\
\hline $20-24$ & $0.535^{*}(0.06)$ & $0.657^{*}(0.13)$ & $0.548^{*}(0.05)$ \\
\hline $25-29$ & $0.463^{*}(0.05)$ & $0.525^{*}(0.10)$ & $0.451^{*}(0.04)$ \\
\hline $30-34$ & $0.438^{*}(0.05)$ & $0.430^{*}(0.09)$ & $0.401^{*}(0.04)$ \\
\hline $35-39$ & $0.448^{*}(0.06)$ & $0.487^{*}(0.10)$ & $0.425^{*}(0.05)$ \\
\hline $40-44$ & $0.465^{*}(0.07)$ & $0.553^{*}(0.14)$ & $0.451^{*}(0.06)$ \\
\hline $45-49$ & $0.539^{*}(0.09)$ & $0.995(0.29)$ & $0.577^{*}(0.09)$ \\
\hline \multicolumn{4}{|c|}{ Education status of Women } \\
\hline \multicolumn{4}{|c|}{ Illiterate } \\
\hline Primary & $0.998(0.05)$ & $0.912(0.08)$ & $0.959(0.11)$ \\
\hline Secondary & $0.798^{*}(0.04)$ & $0.770^{*}(0.06)$ & $0.748^{*}(0.03)$ \\
\hline Higher & $0.506^{*}(0.12)$ & $0.459^{*}(0.05)$ & $0.413^{*}(0.04)$ \\
\hline
\end{tabular}




\begin{tabular}{|c|c|c|c|}
\hline \multicolumn{4}{|c|}{ Education status of husband/partner } \\
\hline \multicolumn{4}{|c|}{ Illiterate } \\
\hline Primary & $0.851(0.11)$ & $1.091(0.27)$ & $0.911(0.11)$ \\
\hline Secondary & $0.783^{*}(0.09)$ & $0.922(0.19)$ & $0.834^{*}(0.08)$ \\
\hline Higher & $0.651(0.24)$ & $0.546^{*}(0.15)$ & $0.534^{*}(0.10)$ \\
\hline Don't Know/missing & $0.346^{*}(0.16)$ & $0.480(0.32)$ & $0.369^{*}(0.14)$ \\
\hline \multicolumn{4}{|c|}{ Occupational status of woman } \\
\hline \multicolumn{4}{|c|}{ Not working } \\
\hline White collar & $0.719(0.36)$ & $1.104(0.36)$ & $0.984(0.27)$ \\
\hline Agricultural worker & $0.928(0.12)$ & $0.875(0.21)$ & $0.906(0.10)$ \\
\hline Service/manual work & $0.927(0.18)$ & $1.487^{*}(0.31)$ & $1.128(0.16)$ \\
\hline Don't know/missing & $1.493(0.57)$ & $1.184(0.67)$ & $1.442(0.46)$ \\
\hline \multicolumn{4}{|c|}{ Occupational status of husband/partner } \\
\hline \multicolumn{4}{|c|}{\begin{tabular}{|l|l} 
Not working &
\end{tabular}} \\
\hline White collar & $0.764(0.21)$ & $1.267(0.46)$ & $0.880(0.18)$ \\
\hline Agricultural worker & $0.760(0.17)$ & $1.482(0.53)$ & $0.917(0.10)$ \\
\hline Service/manual work & $0.810(0.18)$ & $1.301(0.45)$ & $0.939(0.18)$ \\
\hline Don't know/missing & $1.340(0.49)$ & $2.107(1.13)$ & $1.528(0.46)$ \\
\hline \multicolumn{4}{|l|}{ Caste } \\
\hline \multicolumn{4}{|l|}{ Others } \\
\hline $\mathrm{SC}$ & $1.138(0.09)$ & $1.243^{*}(0.11)$ & $1.228^{*}(0.07)$ \\
\hline ST & $1.349^{*}(0.01)$ & $1.435^{*}(0.17)$ & $1.445^{*}(0.09)$ \\
\hline OBC & $1.023(0.08)$ & $1.119(0.08)$ & $1.090^{*}(0.06)$ \\
\hline Don’t know/missing & $1.110(0.13)$ & $1.172(0.17)$ & $1.169^{*}(0.11)$ \\
\hline \multicolumn{4}{|l|}{ Religion } \\
\hline \multicolumn{4}{|l|}{ Hindus } \\
\hline Muslims & $0.992(0.06)$ & $0.791^{*}(0.06)$ & $0.919^{*}(0.04)$ \\
\hline Christians & $0.855(0.09)$ & $1.403^{*}(0.19)$ & $1.024(0.08)$ \\
\hline Others & $0.866(0.12)$ & $0.917(0.13)$ & $0.867(0.08)$ \\
\hline \multicolumn{4}{|l|}{ Place of residence } \\
\hline \multicolumn{4}{|l|}{ Rural } \\
\hline Urban & $0.882(0.07)$ & $0.824^{*}(0.05)$ & $0.786^{*}(0.03)$ \\
\hline \multicolumn{4}{|l|}{ Region } \\
\hline \multicolumn{4}{|l|}{ Northern } \\
\hline Central & $1.414^{*}(0.09)$ & $1.457^{*}(0.10)$ & $1.462^{*}(0.07)$ \\
\hline Eastern & $0.941(0.07)$ & $0.784^{*}(0.08)$ & $0.948(0.05)$ \\
\hline North-eastern & $0.936(0.09)$ & $0.831(0.10)$ & $0.952(0.07)$ \\
\hline Western & $0.897(0.11)$ & $0.755^{*}(0.09)$ & $0.830^{*}(0.07)$ \\
\hline Southern & $1.186(0.15)$ & $0.908(0.90)$ & $0.987(0.08)$ \\
\hline
\end{tabular}

\section{Association between socio-demographic factors and MCH care and outcomes}

In addition to maternal engagement with FHWs, $\mathrm{MCH}$ care service utilisation are also influenced by an array of socio-economic and demographic characteristics. For instance, mothers with less than two children were more likely to have better health care utilisation (such as giving birth at health facilities, ANC visits, higher levels of postnatal care, prescribed set of child immunisation) and child survival rates, relative to mothers with more than two children. The utilisation of $\mathrm{MCH}$ care and child survival varies by the social and religious affiliation, and is also higher among urban residents. In terms of regional disparities, women from Southern India have a higher probability of utilisation of $\mathrm{MCH}$ services relative to women from 
other regions Table 2 and Table 3. These findings are in line with previous studies that documented determinants of maternal and child health care [7-9,54,55].

\section{Robustness Checks}

Following [46], we have used sub-sample analyses to check the robustness of the relationship between the level of FHW engagement and utilisation of $\mathrm{MCH}$ care and child survival in India. We have categorised women who delivered in public health hospitals and those from rural areas as two separate sets of sub-samples.

Results based on the sub-sample of women who delivered in public institutions. Table A2 demonstrates the unadjusted and adjusted effects of engagement with FHWs on the utilisation of $\mathrm{MCH}$ services for the sub-sample of women who delivered only in public health care institutions. After controlling for all other potential socioeconomic and demographic confounders, the adjusted probabilities suggest that differences in the likelihood of MCH care utilisation by the level of FHW engagement is not statistically different in the sample of women who delivered in public institutions relative to the overall sample. Specifically, we observe that poor women with high levels of FHW engagement have a 6.57 times $(\mathrm{p}<0.01)$ higher likelihood of having four or more ANC visits and they are 2.59 times $(\mathrm{p}<0.01)$ more likely to have had an institutional delivery in public health facilities. Moreover, their children have a 2.38 times $(p<0.01)$ higher likelihood of CFI and they are 4.34 times $(p<0.01)$ more likely to receive PNC relative to those with low levels of FHW engagement. Note that high levels of FHW engagement is also beneficial for non-poor women, who are also nearly two times more likely to access MCH services if they have a high level of FHW engagement. In keeping with the analyses based on the full sample, analyses of the sub-sample of women who delivered in public health institutions also show that after controlling for all socio-economic and demographic characteristics, the differences in the odds of obtaining $\mathrm{MCH}$ care by the level of engagement with FHWs is higher among poor compared to the non-poor women. 


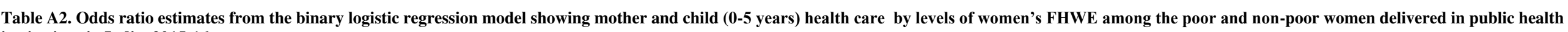
institutions in India, 2015-16

\begin{tabular}{|c|c|c|c|c|c|c|c|c|c|c|c|c|}
\hline \multirow[b]{3}{*}{ Predictor Variables } & \multicolumn{3}{|c|}{ Antenatal care ( 4 or $>4$ times) } & \multirow{2}{*}{\multicolumn{3}{|c|}{$\begin{array}{c}\text { Place of delivery (Public Institutions) } \\
\text { Odds Ratio (SE) }\end{array}$}} & \multirow{2}{*}{\multicolumn{3}{|c|}{$\begin{array}{l}\text { Child Full Immunization (12-23 months) } \\
\text { Odds Ratio (SE) }\end{array}$}} & \multirow{2}{*}{\multicolumn{3}{|c|}{$\begin{array}{l}\text { Infant Postnatal care (within } 2 \text { days of delivery) } \\
\text { Odds Ratio (SE) }\end{array}$}} \\
\hline & & dds Ratio (SE & & & & & & & & & & \\
\hline & $\begin{array}{c}\text { Poor } \\
(n=51153)\end{array}$ & $\begin{array}{l}\text { Non-Poor } \\
(n=54462)\end{array}$ & $\begin{array}{c}\text { Total } \\
(n=105615)\end{array}$ & $\begin{array}{c}\text { Poor } \\
(n=130132)\end{array}$ & $\begin{array}{c}\text { Non-Poor } \\
(n=129495)\end{array}$ & $\begin{array}{c}\text { Total } \\
(n=259627)\end{array}$ & $\begin{array}{c}\text { Poor } \\
(n=20520)\end{array}$ & $\begin{array}{c}\text { Non-Poor } \\
(n=18783)\end{array}$ & $\begin{array}{c}\text { Total } \\
(n=39303)\end{array}$ & $\begin{array}{c}\text { Poor } \\
(n=51153)\end{array}$ & $\begin{array}{l}\text { Non-Poor } \\
(n=54462)\end{array}$ & $\begin{array}{c}\text { Total } \\
(n=105615)\end{array}$ \\
\hline
\end{tabular}

\section{Panel A (Unadjusted)}

\begin{tabular}{|c|c|c|c|c|c|c|c|c|c|c|c|c|}
\hline Low $^{\circledR}$ & & & & & & & & & & & & \\
\hline Medium & $2.124^{*}(0.07)$ & $1.559^{*}(0.04)$ & $1.699^{*}(0.03)$ & $1.752^{*}(0.03)$ & $1.393^{*}(0.02)$ & $1.533^{*}(0.02)$ & $1.549^{*}(0.06)$ & $1.558^{*}(0.06)$ & $1.553^{*}(0.04)$ & $1.891^{*}(0.08)$ & $1.676^{*}(0.06)$ & $1.774^{*}(0.05)$ \\
\hline High & $6.566^{*}(0.21)$ & $2.326^{*}(0.06)$ & $3.430^{*}(0.06)$ & $2.594^{*}(0.04)$ & $2.681^{*}(0.03)$ & $2.342^{*}(0.02)$ & $2.381^{*}(0.09)$ & $2.158^{*}(0.09)$ & $2.289^{*}(0.06)$ & $4.337^{*}(0.16)$ & $3.088^{*}(0.10)$ & $3.593^{*}(0.08)$ \\
\hline
\end{tabular}

\section{Panel B (Adjusted)}

Level of FHWE

\begin{tabular}{|l}
\hline Level of \\
\hline Low $^{\otimes}$ \\
\hline
\end{tabular}

\begin{tabular}{l} 
Low $^{\circledR}$ \\
\hline Medium \\
\hline
\end{tabular}

\begin{tabular}{l|l} 
& \\
\hline High & $1.976^{*}(0.07)$ \\
\hline
\end{tabular}

${ }^{a}$ Standard Error in the parentheses;

( Reference group;

${ }^{*} p<0.05$;

FHWE: Frontline Health Worker Interaction

CFI: Child Full Immunization.

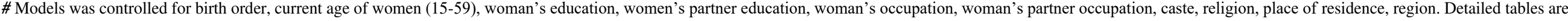
presented in Table S4. 
Results based on women from rural areas. The analyses of the sub-sample of women from rural areas further strengthen our argument that engagements with FHWs help women in accessing MCH care and child survival outcomes. We observe that compared to poor women with low FHWI, those with high FHWI in rural areas have 8.73 times $(\mathrm{p}<0.01)$ higher likelihood of having more than four ANC visits and they are 2.58 times $(\mathrm{p}<0.01)$ more likely to have institutional delivery. Further, their children have 2.66 times $(p<0.01)$ higher probability of CFI and they are 4.81 times $(\mathrm{p}<0.01)$ more likely to seek PNC relative to those with low FHW engagement. Non-poor women also have about two to three times higher probability of accessing MCH services if they have a high level of FHWE. Thus, once again the results suggest that after controlling for all the socio-economic and demographic characteristics, differences in the odds of obtaining $\mathrm{MCH}$ care by the level of engagement with FHWs are higher among poor compared to the non-poor Table A3.

Table A3. Hazard ratio estimates from the Cox proportional hazard regression model: child survival outcome by mother's level of FHWE among the poor and non-poor women delivered in public health institutions in India, 2015-16

\begin{tabular}{|c|c|c|c|}
\hline \multirow{2}{*}{ Predictor Variables } & \multicolumn{3}{|c|}{ Hazard Ratio $\left(\mathrm{SE}^{\mathrm{a}}\right)$} \\
\hline & Poor $(n=71446)$ & Non-Poor $(n=69582)$ & Total $(n=141028)$ \\
\hline \multicolumn{4}{|c|}{ Panel A (Unadjusted) } \\
\hline \multicolumn{4}{|c|}{ Level of FHWE } \\
\hline \multicolumn{4}{|l|}{ Low $^{\circledR}$} \\
\hline Medium & $0.545^{*}(0.03)$ & $0.646^{*}(0.05)$ & $0.580^{*}(0.03)$ \\
\hline High & $0.208^{*}(0.02)$ & $0.264^{*}(0.03)$ & $0.227^{*}(0.01)$ \\
\hline \multicolumn{4}{|l|}{ Panel B (Adjusted) \# } \\
\hline \multicolumn{4}{|l|}{ Level of FHWE } \\
\hline \multicolumn{4}{|l|}{ Low $^{\circledR}$} \\
\hline Medium & $0.547^{*}(0.04)$ & $0.625^{*}(0.5)$ & $0.576^{*}(0.03)$ \\
\hline High & $0.210^{*}(0.02)$ & $0.248^{*}(0.2)$ & $0.225^{*}(0.01)$ \\
\hline
\end{tabular}

${ }^{\text {a }}$ Standard Error.

${ }^{\circledR}$ Reference group.

${ }^{*} p<0.05$.

FHWE: Frontline Health Worker Interaction.

\# Model was controlled for birth order, current age of women (15-59), woman's education, women's partner education, woman's occupation, woman's partner occupation, caste, religion, place of residence, region. Detailed tables are presented in Table S5.

Similarly, the analyses of child survival outcomes from the sub-sample of women from rural areas show that the differences in the hazard of death by the level of mother's engagement 
with FHWs for an under-five child are significantly low in women with a higher FHWE compared to their counterparts. Such patterns also not vary by their economic status net of other socio-economic and demographic characteristics Table A2.

\section{Discussion}

The focus of previous studies on the issue of 'influence of FHWs on MCH care and outcomes' has been on the relationship between women's engagement with CHWs in general and ASHAs in particular. Furthermore, these studies have typically focused on case studies, observational or experimental studies conducted in a specific geographical area mostly using small samples $[13,14,18,30,31,41,45]$. In this study, we have addressed a research gap by using a nationally representative sample and adopting a comprehensive definition of FHWs to investigate the influence of the level of women's engagement with FHWs on various MCH care and outcome indicators. Our analyses find that the level of women's engagement with FHWs is positively associated with $\mathrm{MCH}$ care and outcomes, irrespective of the socioeconomic and demographic characteristics of the women. The findings also suggest that poor women have a greater chance of benefiting from the interaction with FHWs compared to nonpoor. The analysis of sub-samples of women who delivered only in public health facilities and rural women is consistent with previous evidence and supports the robustness of our study. Thus, our study supports the argument of Close To Community (CTC) potential of FHWs for expanding the utilisation of $\mathrm{MCH}$ services especially among the poor women, which often stand at the fringes of the health system $[7,53,55]$. Our findings are in keeping with previous studies that examined the role of FHWs in improving MCH care [21,22,24,27,41], and microlevel investigations in India $[13,14,18,30,31,41,45]$.

Intervention through demand-side determinants and demand-side financing are well discussed and debated strategies in policy and programs to ensure equity in $\mathrm{MCH}$ care and outcomes $[5,8,10,11,34]$. However, enhancing engagement with FHWs can be just as cost- 
effective, results-driven and are shown to be a proven intervention for bringing equity in $\mathrm{MCH}$ care and outcomes $[28,56]$. However, previous studies have reported that factors such as a lack of skills, low qualifications, the multitasking nature of their job, low incentives, and low recognition is discouraging many FHWs from remaining in this profession $[40,42,44,45]$. Addressing the shortage of FHWs, enhancing skills and the use of innovative tools to track pregnancies and $\mathrm{MCH}$ care can be a more cost-effective strategy to bring equity in $\mathrm{MCH}$ services utilisation and outcomes in India and other developing countries [19,26,32]. Findings and recommendations from previous studies in other geographical contexts also support our recommendations $[23,56]$.

\section{Limitations of the study and scope of future research}

Our study is unable to document three aspects of the role of FHWs in improving MCH care and outcomes in the Indian context. First, we are unable to comment on the professional skills and expertise of the FHWs as the NFHS dataset does not provide this information. Second, we are unable to identify reasons for the non-interaction of women with FHWs. Third, although information in the NFHS data on the index of level of engagement with FHWs covers the quantity and quality of interaction, it is not a sufficiently comprehensive measure to capture quality in a true sense. Thus, future rounds of NFHS must enhance the module on the interaction of FHWs with respondents, and collect comprehensive information on the quantity and quality of their engagement with FHWs to identify the constraints facing those who do not engage with FHWs.

\section{Conclusion}

Our findings have identified FHWs as an integral part of the health system with the potential to make a significant difference to the health of women and children from poor households. FHWs alongside a high quality public healthcare infrastructure can be efficient forms of 
supply-side pathways to address under-utilisation of MCH services and improve maternal and child health outcomes, especially among economically disadvantaged people, particularly those living in areas with poor infrastructure. FHWs can work as an interface between people and programmes, and can play a crucial role in motivating people to access health services. FHWs also help in the identification and tracking of potentially vulnerable groups. The role of FHWs in the government health system needs to be enhanced by improving skills, working environment, and greater financial incentives. Also, there is a need to understand barriers in the lower engagement of pregnant women with FHWs.

\section{Declarations}

\section{Ethics approval and consent to participate}

Ethical approval for the National Family Health Survey was given institutional review board of the International Institute for Population Sciences (IIPS), Mumbai, India.

\section{Consent for publication}

This study is an independent research carried out by authors using a publicly avaibale data. Thus, doesn't require a third party consent.

\section{Availability of data and material}

The datasets used in this study are publically available at https://dhsprogram.com/what-wedo/survey/survey-display-355.cfm.

\section{Competing interests}

The authors declare that they have no competing interests

\section{Funding}

None to declare 


\section{Authors' contributions}

AR \& SG conceptualized the study; SKS \& SG prepared the dataset and conducted the analyses; SKS, SG, SKS, and AJ wrote the first draft; AR \& SG validated and finalized the draft.

\section{Acknowledgments}

None to declare

\section{References}

1. WHO. Immunisation. Global health observatory data repository. 2019 [internet]. Available from https://apps.who.int/gho/data/node.main.A824?lang=en.

2. United Nations Inter-agency Group for Child Mortality Estimation (UN IGME). Levels and trends in child mortality: report 2019, estimates developed by the United Nations Inter-agency Group for Child Mortality Estimation. New York: United Nations Children's Fund; 2019.

3. IIPS, ICF. National Family Health Survey (NFHS-4) 2015-16.: India. Mumbai: International Institute for Population Sciences; 2017.

4. Carvalho N, Rokicki S. The impact of India's Janani Suraksha Yojana conditional cash transfer programme: A replication study. The Journal of Development Studies. 2019 May 4;55(5):989-1006. doi:10.1080/00220388.2018.1506578.

5. Powell-Jackson T, Pereira SK, Dutt V, Tougher S, Haldar K, Kumar P. Cash transfers, maternal depression and emotional well-being: Quasi-experimental evidence from India's Janani Suraksha Yojana programme. Social Science and Medicine. 2016 Aug 1;162:210-8. doi.org/10.1016/j.socscimed.2016.06.034.

6. Lim SS, Dandona L, Hoisington J. a, James SL, Hogan MC, Gakidou E. India's Janani Suraksha Yojana, a conditional cash transfer programme to increase births in health 
facilities: an impact evaluation. Lancet. 2010;375(9730):1939-2050.. PMID: 20569841 Doi: 10.1016/S0140-6736(10)60744-1.

7. Singh PK, Rai RK, Singh L. Examining the effect of household wealth and migration status on safe delivery care in urban India, 1992-2006. PLoS One. 2012 Sep 7; 7(9):e44901. doi.org/10.1371/journal.pone.0044901.

8. Mohanty SK. Multiple deprivations and maternal care in India. International Perspectives on Sexual and Reproductive Health. 2012 March 38 (1), 6-14. Available from https://www.guttmacher.org/journals/ipsrh/2012/03/multiple-deprivations-andmaternal-care-india.

9. Balarajan Y, Selvaraj S, Subramanian SV. India: towards universal health coverage 4. Health care and equity in India. Lancet. 2011; 377:505-15. doi.org/10.1016/S0140$\underline{6736(10) 61894-6 .}$.

10. Subramanian, S. V., Ackerson, L. K., Davey Smith, G., John, N. A., 2009. Association of maternal height with child mortality, anthropometric failure, and anemia in India. JAMA 301(16), 1691-1701. https://doi.org/10.1001/jama.2009.548.

11. Mohanty SK, Pathak PK. Rich-poor gap in utilization of reproductive and child health services in India, 1992-2005. Journal of biosocial science. 2009 May 1; 41(3):381. doi:10.1017/S002193200800309X.

12. Ghei K, Agarwal S, Subramanyam MA, Subramanian SV. Association between child immunization and availability of health infrastructure in slums in India. Archives of pediatrics and adolescent medicine. 2010 Mar 1;164(3):243-9. doi: 10.1001/archpediatrics.2009.277.

13. Wagner AL, Porth JM, Bettampadi D, Boulton ML. Have community health workers increased the delivery of maternal and child healthcare in India?. Journal of Public Health. 2018 Jun 1;40(2):e164-70. doi.org/10.1093/pubmed/fdx087. 
14. Tripathy P, Nair N, Sinha R, Rath S, Gope RK, Rath S, Roy SS, Bajpai A, Singh V, Nath V, Ali S. Effect of participatory women's groups facilitated by Accredited Social Health Activists on birth outcomes in rural eastern India: a cluster-randomised controlled trial. The Lancet Global Health. 2016 Feb 1;4(2):e119-28. Doi:10.1016/S2214-109X(15)00287-9.

15. Pallikadavath, S., Singh, A., Ogollah, R., Dean, T., Stones, W., 2013. Human Resource inequalities at the base of India's Public healthcare system. Health and Place 23, 26-32. http://dx.doi.org/10.1016/j.healthplace.2013.05.003.

16. Hazarika I. Health workforce in India: assessment of availability, production and distribution. WHO South East Asia J. Public Health. 2013 2(2), 106-112. https://doi.org/10.4103/2224-3151.12294.

17. Koehn HJ, Zheng S, Houser RF, O'Hara C, Rogers BL. Remuneration systems of community health workers in India and promoted maternal health outcomes: a crosssectional study. BMC Health Services Research. 2020 Dec 1;20(1):48. doi.org/10.1186/s12913-019-4883-6.

18. Wagner AL, Xia L, Ghosh A, Datta S, Pandey P, Santra S, Chattopadhyay S, Nandi U, Mazumder T, Joshi S, Pal J. Using community health workers to refer pregnant women and young children to health care facilities in rural West Bengal, India: A prospective cohort study. PloS one. 2018 Jun 21; 13(6):e0199607. doi.org/10.1371/journal.pone.0199607.

19. WHO. National health workforce accounts: implementation guide, World Health Organization, Geneva Press; 2018. Licence: CC BY-NC-SA 3.0 IGO. Available from https://apps.who.int/iris/rest/bitstreams/1090981/retrieve.

20. Singh S, Doyle P, Campbell OM, Mathew M, Murthy GV. Referrals between public sector health institutions for women with obstetric high risk, complications, or 
emergencies in India-A systematic review. PloS one. 2016 Aug 3; 11(8):e0159793. doi:10.1371/journal.pone.0159793.

21. Kane S, Kok M, Ormel H, Otiso L, Sidat M, Namakhoma I, Nasir S, Gemechu D, Rashid S, Taegtmeyer M, Theobald S. Limits and opportunities to community health worker empowerment: a multi-country comparative study. Social Science and Medicine. 2016 Sep 1;164:27-34. doi.org/10.1016/j.socscimed.2016.07.019.

22. Mselle LT, Moland KM, Mvungi A, Evjen-Olsen B, Kohi TW. Why give birth in health facility? Users' and providers' accounts of poor quality of birth care in Tanzania. BMC health services research. 2013 Dec 1;13(1):174. doi.org/10.1186/1472-6963-13-174.

23. Mitchell AD, Bossert TJ, Yip W, Mollahaliloglu S. Health worker densities and immunization coverage in Turkey: a panel data analysis. Human resources for health. 2008 Dec 1;6(1):29. doi.org/10.1186/1478-4491-6-29.

24. Tran NT, Portela A, de Bernis L, Beek K. Developing capacities of community health workers in sexual and reproductive, maternal, newborn, child, and adolescent health: a mapping and review of training resources. PLoS One. 2014 Apr 15;9(4):e94948. doi.org/10.1371/journal.pone.0094948.

25. Alam K, Tasneem S, Oliveras E. Performance of female volunteer community health workers in Dhaka urban slums. Social science and medicine. 2012 Aug 1;75(3):511-5. doi.org/10.1016/j.socscimed.2012.03.039.

26. WHO. Working for health and growth: investing in the health workforce. Report of the High-Level Commission on Health Employment and Economic Growth. Geneva: World Health Organization Press; 2016b. Available from http://apps.who.int/iris/bitstream/10665/250047/1/9789241511308-eng.pdf.

27. Oliver M, Geniets A, Winters N, Rega I, Mbae SM. What do community health workers have to say about their work, and how can this inform improved programme design? A 
case study with CHWs within Kenya. Global health action. 2015 Dec 1; 8(1):27168. doi.org/10.3402/gha.v8.27168.

28. Perry H, Zulliger R. How effective are community health workers? An overview of current evidence with recommendations for strengthening community health worker programmes to accelerate progress in achieving the health-related Millennium Development Goals. Baltimore: Johns Hopkins Bloomberg, School of Public Health; 2012. Available from https://www.everywomaneverychild.org/wpcontent/uploads/2016/11/review-of-chw-effectiveness-for-mdgs-sept2012.pdf.

29. WHO. Global strategy on human resources for health: Workforce 2030. Geneva: World Health Organization Press; 2016a. Available from https://apps.who.int/iris/bitstream/handle/10665/250368/9789241511131eng.pdf?sequence $=1$.

30. Lyngdoh T, Neogi SB, Ahmad D, Soundararajan S, Mavalankar D. Intensity of contact with frontline workers and its influence on maternal and newborn health behaviors: cross-sectional survey in rural Uttar Pradesh, India. Journal of Health, Population and Nutrition. 2018 Dec 1;37(1):2. https://doi.org/10.1186/s41043-017-0129-6.

31. Seth A, Tomar S, Singh K, Chandurkar D, Chakraverty A, Dey A, Das AK, Hay K, Saggurti N, Boyce S, Raj A. Differential effects of community health worker visits across social and economic groups in Uttar Pradesh, India: a link between social inequities and health disparities. International journal for equity in health. 2017 Dec 1;16(1):46. https://doi.org/10.1186/s12939-017-0538-6.

32. Park H. An introduction to logistic regression: from basic concepts to interpretation with particular attention to nursing domain. Journal of Korean Academy of Nursing. 2013 Apr 1;43(2):154-64. doi: 10.4040/jkan.2013.43.2.154. 
33. Rao KS. Do We Care? India's Health System. Delhi: Oxford University Press India; 2017. Available from https://india.oup.com/product/do-we-care-9780199469543?

34. Joe W, Perkins JM, Kumar S, Rajpal S, Subramanian SV. Institutional delivery in India, 2004-14: unravelling the equity-enhancing contributions of the public sector. Health policy and planning. 2018 Jun 1;33(5):645-53. doi.org/10.1093/heapol/czy029.

35. Powell-Jackson T, Mazumdar S, Mills A. Financial incentives in health: New evidence from India's Janani Suraksha Yojana. Journal of health economics. 2015 Sep 1; 43: 15469. doi: 10.1016/j.jhealeco.2015.07.001.

36. Sidney K, Diwan V, El-Khatib Z, De Costa A. India's JSY cash transfer program for maternal health: Who participates and who doesn't-a report from Ujjain district. Reproductive health. 2012 Dec 1;9(1):2. doi.org/10.1186/1742-4755-9-2 .

37. GOI. A Strategic Approach to Reproductive, Maternal, New-born child and Adolescent Health (RMNCH+A) in India: For healthy mother and child. New Delhi: Ministry of Health and Family Welfare [MoHFW], Government of India; 2013. Available from http://nhm.gov.in/images/pdf/RMNCH+A/RMNCH+A_Strategy.pdf.

38. GOI. 2018. Guidelines on midwifery services in India 2018. New Delhi: Ministry of Health and Family Welfare [MoHFW], Government of India; 2018. Available form https://nhm.gov.in/New_Updates_2018/NHM_Components/RMNCHA/MH/Guidelin es/Guidelines_on_Midwifery_Services_in_India.pdf.

39. Ved R, Scott K, Gupta G, Ummer O, Singh S, Srivastava A, George AS. How are gender inequalities facing India's one million ASHAs being addressed? Policy origins and adaptations for the world's largest all-female community health worker programme. Hum. Resour. Health. 2019. 17 (3), 1-15. doi.org/10.1186/s12960-0180338-0. 
40. Saprii L, Richards E, Kokho P, Theobald S. Community health workers in rural India: analysing the opportunities and challenges Accredited Social Health Activists (ASHAs) face in realising their multiple roles. Human resources for health. 2015 Dec; 13(1):1-3. doi.org/10.1186/s12960-015-0094-3.

41. Agrawal PK, Agrawal S, Ahmed S, Darmstadt GL, Williams EK, Rosen HE, Kumar V, Kiran U, Ahuja RC, Srivastava VK, Santosham M. Effect of knowledge of community health workers on essential newborn health care: a study from rural India. Health policy and planning. 2012 Mar 1;27(2):115-26. doi.org/10.1093/heapol/czr018.

42. Bhatia K. Community health worker programs in India: a rights-based review. Perspectives in public health. 2014 Sep; 134(5):276-82. doi: $10.1177 / 1757913914543446$.

43. Houweling T. a J, Tripathy P, Nair N, Rath S, Rath S, Gope R, et al. The equity impact of participatory women's groups to reduce neonatal mortality in India: secondary analysis of a cluster-randomised trial. Int J Epidemiol. 2013; 42: 520-32. Doi: 10.1093/ije/dyt012.

44. Scott K, George AS, Ved RR. Taking stock of 10 years of published research on the ASHA programme: examining India's national community health worker programme from a health systems perspective. Health research policy and systems. 2019 Dec 1; 17(1): 29. doi.org/10.1186/s12961-019-0427-0.

45. Rao KD, Srivastava S, Warren N, Mayra K, Gore A, Das A, Ahmed S. Where there is no nurse: an observational study of large-scale mentoring of auxiliary nurses to improve quality of care during childbirth at primary health centres in India. BMJ open. $2019 \mathrm{Jul}$ 1;9(7):e027147. doi:10.1136/bmjopen-2018-027147. 
46. Lu X, White H. Robustness checks and robustness tests in applied economics. Journal of $\quad$ Econometrics. $\quad 2014 ; \quad 178 \quad$ (P1): $194-206$. https://doi.org/10.1016/j.jeconom.2013.08.016.

47. International Institute for Population Sciences (IIPS) [India], Ministry of Health and Family Welfare [MoHFW] [India], and ICF, India. Standard Demographic and Health Surveys, 2015-16 [IAKR74FL.DTA]; 2017. Database: The Demographic Health $\begin{array}{llll}\text { Surveys } & \text { (DHS) } & \text { [internet]. }\end{array}$ https://dhsprogram.com/customcf/legacy/data/download_dataset.cfm?Filename=IAK $\underline{\text { R74DT.ZIPandTp=1 andCtry_Code }=I \text { Aandsurv } \_i d=355 \text { anddmode }=\mathrm{cf}}$.

48. Filmer D, Scott K. Assessing asset indices. Demography. 2012; 49: 359-392. doi.org/10.1007/s13524-011-0077-5.

49. Fisher LD, Lin DY. Time-dependent covariates in the Cox proportional- hazards regression model. Annu Rev Public Health. 1999; 20:145-57. doi: 10.1146/annurev.publhealth.20.1.145.

50. Retherford RD, Choe MK. Statistical models for causal analysis. New York: John Wiley and Sons, Inc; 1993. Available from https://onlinelibrary.wiley.com/doi/book/10.1002/9781118033135.

51. Harrell Jr, FE. Cox Proportional Hazards Regression model. In: Regression Modelling Strategies with applications to linear models, logistic regression, and survival analysis. New York: Springer Series in Statistics, Springer Science+Business Media, LLC; 2001. Doi: $10.1007 / 978-1-4757-3462-1$.

52. Cox DR. Partial likelihood, Biometrika. 1975; 62 (2), 269-276. doi.org/10.1093/biomet/62.2.269. 
53. Pathak PK, Singh A, Subramanian SV. Economic inequalities in maternal health care: prenatal care and skilled birth attendance in India, 1992-2006. PloS one. 2010; 5(10): e13593. doi:10.1371/journal.pone.0013593.

54. Singh PK, Kumar C, Rai RK, Singh L. Factors associated with maternal healthcare services utilization in nine high focus states in India: a multilevel analysis based on 14 385 communities in 292 districts. Health Policy Plan. 2014; 29(5), 542-559. doi:10.1093/heapol/czt039.

55. Subramanian SV, Smith GD, Subramanyam M. Indigenous health and socioeconomic status in India. PLoS Med. 2006; 3(10), e421. doi.org/10.1371/journal.pmed.0030421.

56. Yuan B, Malqvist M, Trygg N, Qian X, Ng N, Thomsen S. What interventions are effective on reducing inequalities in maternal and child health in low- and middleincome settings? A systematic review. BMC Public Health. 2014; 14 (634), 1-14. doi.org/10.1186/1471-2458-14-634.

\section{Supporting information}

S1 Fig. Maternal health care by FHWE for Poor and Non-Poor women in India, 2015-16. (TIFF).

S2 Fig. Child health care and outcomes by FHWE for Poor and Non-Poor women in India, 2015-16. (TIFF).

S3 Fig. ANCs utilisation by FHWE for Poor and Non-poor women delivered in public health institutions in India, 2015-16. (TIFF).

S4 Fig. Child health care and outcomes by FHWE for Poor and Non-poor women delivered in public health institutions in India, 2015-16. (TIFF). 
S5 Fig. Kaplan-Meier survival estimates by level of FHWE for the Poor and Non-Poor women delivered in public health institutions in India, 2015-16. (TIFF).

S1 Table. Descriptive statistics of background characteristics by maternal and child health outcomes in India, 2015-16. (DOCX).

S2 Table. Descriptive statistics of background characteristics by maternal and child health outcomes among women delivered in public health institutions in India, 2015-2016. (DOCX).

S3 Table. Descriptive statistics of background characteristics by maternal and child health outcomes in India, 2015-16. (DOCX).

S4 Table. Odds ratio by using Binary Logistic Regression (BLR) model of mother and child (0-5 years) health outcomes by levels of FHWE among the poor and nonpoor women delivered in public health institutions in India, 2015-16. (DOCX).

S5 Table. Hazard ratio by using Cox Proportional Hazard regression model of mother and child (0-5 years) health outcomes by FHWE Level, among the poor and nonpoor women delivered in public health institutions in India, 2015-16. (DOCX).

S6 Table. Odds ratio by using Binary Logistic Regression (BLR) model of mother and child (0-5 years) health outcomes by levels of FHWE among the poor and nonpoor of rural women in India, 2015-16. (DOCX).

S7 Table. Hazard ratio by using Cox Proportional Hazard regression model of child survival outcome by FHWE Level, among the poor and non-poor of rural women in India, 2015-16. (DOCX). 
Figures

\section{Image not available with this version}

\section{Figure 1}

Kaplan-Meier child survival estimates by level of mother's FHWE among the poor and non-poor households in India, 2015-16. (TIFF).

\section{Supplementary Files}

This is a list of supplementary files associated with this preprint. Click to download.

- SupplementaryTables.docx

- SupplementaryFigureswithheadings.docx 